\title{
Classic adsorption isotherms incorporated in modern surface complexation models: Implications for sorption of actinides
}

\author{
By D. A. Kulik* \\ Nuclear Energy and Safety Research Department, Laboratory for Waste Management, Paul Scherrer Institute, 5232 Villigen PSI, Switzerland
}

(Received August 12, 2005; accepted in revised form March 28, 2006)

\author{
Adsorption isotherm / Langmuir / Frumkin / \\ Surface complexation modeling / \\ Surface activity coefficient term / Uranyl sorption
}

Summary. Computer-aided surface complexation models (SCMs) are widely used in describing mineral-water interface reactions such as sorption of actinides onto (hydr)oxides and clays. Most SCMs are built upon balances of surface binding sites. In fact, such models can reproduce only competitive Langmuir isotherms, plus optional electrostatic corrections. Hence, it may be difficult to extend such SCMs to some real-surface phenomena (site heterogeneity, lateral interactions, surface precipitation) described in isotherms other than Langmuir. In this contribution, a new approach to overcome this difficulty is presented which does not use surface site balances, is not restricted only to Langmuir isotherms, and can be implemented within the Gibbs energy minimization solvers of chemical (adsorption) equilibria. It is suggested to define the ideal behavior of a surface species using a linear isotherm only. Conversely, an adsorption isotherm equation of choice can be split into a linear term (involving the standard-state density and the equilibrium constant referenced to infinite dilution) and a non-linear surface activity coefficient term (SACT, involving the site density parameter). A simple method is proposed for deriving a SACT for the monodentate surface binding from the Langmuir isotherm. This method is then applied to obtain SACTs for mono-, bi-, tri- and tetra-dentate binding from the "quasi-chemical approximation" isotherm, as well as a SACT accounting for non-ideal lateral interactions between surface species from the Frumkin isotherm. The new approach is illustrated by modeling $\mathrm{U}^{\mathrm{VI}}$ adsorption on goethite at ambient conditions using a GEM SCM. It is shown that SACTs are useful at moderate- to high surface coverage, but only when the site density parameter is fixed from independent (crystallographic) data and not adjusted to fit the titration data. Ways to enhance SCMs with BET, Freundlich and other isotherms of interest for retention of actinides and fission products on mineral surfaces are also discussed.

\section{Introduction}

Reactivity of mineral-water interfaces is a major topic in aquatic, soil and nuclear waste geochemistry [1-3]. However, generally accepted thermodynamic models and data

\footnotetext{
*E-mail: dmitrii.kulik@psi.ch.
}

bases for adsorption on mineral surfaces are not yet available. One reason might be that the required conventions on standard and reference states for surface species are not established so far. Hence, it is not clear how to compare the known intrinsic adsorption constants referenced to different (already proposed) states. Another reason might be that, without proper conventions, the ideal adsorption behavior cannot be established, so expressions of activity coefficients of surface species as functions of surface coverage and composition cannot be defined.

The experience of existing SCMs based on mole balances for surface sites and on the law of mass action (LMA) for adsorption reactions [3,4], especially the success of the multi-site non-electrostatic sorption model by Bradbury and Baeyens [5-11] for radionuclides and related cations on montmorillonite and illite, show that SCMs do account for some non-ideal effects, even though the non-electrostatic activity coefficients of surface species are usually ignored or assumed to cancel out in LMA expressions [1]. As an alternative, semi-empirical equations for macroscopic adsorption isotherms $[3,12,13]$ were successfully used in describing (ad)sorption in relatively simple experimental systems [14-19]. The classic Langmuir isotherm reflects the saturation of binding sites in the surface monolayer. Other isotherms account for more subtle non-ideal effects related to: multi-dentate binding (quasi-chemical approximation (QCA) isotherm [20]); lateral interactions (Frumkin isotherm); surface condensation/precipitation (BET isotherm); or the energetic site heterogeneity (Freundlich isotherm). In this respect, pertinent questions are: (1) what is the relationship between classic isotherms and site-balance-based LMA SCMs; (2) how to distinguish between ideal and non-ideal contributions in isotherm equations; and (3) how to incorporate these non-ideal contributions (i.e. surface activity coefficients) into a general thermodynamic model of adsorption.

It is known that site-balance based LMA SCMs refer to the infinite dilution reference state [21]. In the nonelectrostatic case, they should exactly reproduce (competitive) Langmuir isotherms for monodentate monolayer binding [3]. If this behavior is considered as "ideal" then the electrostatic (Coulomb) term should be viewed as the only kind of surface activity coefficient [22-24]. As discussed below, the main problem with this approach is that intrinsic adsorption constants $K^{\text {int }}$ used there refer to 
a "full-coverage" standard state, which depends on the selected value of site number density $N_{\mathrm{C}}$ (or sorption capacity $q_{\mathrm{C}}$ ) parameter. Therefore, the numerical value of $K^{\text {int }}$ is only valid in conjunction with the $N_{\mathrm{C}}$ value applied in fitting titration data to obtain the $K^{\text {int }}$ value. Hence, for different site densities, even for the same adsorbate and/or the same sorbent, intrinsic constants $K^{\text {int }}$ may not be directly comparable. Another drawback refers to the multi-site adsorption: one site balance constraint must be included per each site type (this case corresponds to the discrete-site [16] or multiple-site [3,18] Langmuir isotherm). However, in the MUSIC approach [25], or for complex-surface minerals such as clays having many site types, this makes the SCM formulation cumbersome and slows down the calculations. Third limitation is that it is difficult to construct a SCM for poly-dentate surface species without "cheating" the LMA site balance framework. This might also be the reason why isotherms other than Langmuir were not yet implemented in LMA modeling codes.

The main objective of this paper was to overcome these problems by introducing a new thermodynamic approach which does not involve site balances, is not limited only to Langmuir isotherms, and can be used within GEM (Gibbs energy minimization) codes to compute aquatic adsorption equilibria only in elemental stoichiometry basis. In this approach, it is suggested that the only kind of ideal behavior of a surface species is the linear isotherm which refers to an infinite-dilution reference state and a unimolal standard state with the same surface density $\Gamma_{\mathrm{o}}$ for any adsorbed species at any mineral surface [26]. This makes it possible to split an adsorption isotherm equation of choice to a linear ideal part (determined solely by the equilibrium constant $K_{\mathrm{S}}$ ), and a non-ideal part represented by a specific expression of the surface activity coefficient term (SACT).

The second goal of this contribution was to develop a simple method for such splitting, first by deriving a SACT expression for monodentate surface binding from the Langmuir isotherm (also in the competitive case). The new method is then applied to obtain a SACT expression for mono-, bi-, tri- and tetra-dentate binding from the QCA isotherm [20]. Finally, a SACT expression which accounts for the "soft" lateral interactions between surface-bound species is derived from the Frumkin isotherm. In GEM SCMs, these SACTs replace the asymptotically correct but non-rigorous "surface activity terms" (SAT) suggested earlier [26,27]. All surface species belonging to one site type obey the same SACT correction, many site types can be allocated to one surface type, and several surface types (faces) can be allocated to one sorbent, all together forming a sorption phase.

The third aim was to illustrate how the derived SACT expressions can influence the modeled GEM SCM curves using some literature data for $\mathrm{U}^{\mathrm{VI}}$ adsorption on goethite at ambient conditions at medium- to high surface coverage. As all SACT depend mainly on the site density parameter $\Gamma_{\mathrm{C}}$, the emphasis was on the model sensitivity to the choice of this parameter. Finally, the model sensitivity to second-order effects of "dentateness" and lateral interaction parameters was also explored.

\section{Thermodynamic methods}

Chemical potential of any solute chemical species B at equilibrium is given [22] by

$$
\mu_{\mathrm{B}}=\mu_{\mathrm{B}}^{\mathrm{o}}+R T \ln a_{\mathrm{B}}=\mu_{\mathrm{B}}^{\mathrm{o}}+R T \ln r_{\mathrm{B}}+R T \ln \gamma_{\mathrm{B}}
$$

where numerical values of the relative activity $a_{\mathrm{B}}=r_{\mathrm{B}} \gamma_{\mathrm{B}}$, the relative content $r_{\mathrm{B}}$, and the activity coefficient $\gamma_{\mathrm{B}}$ all depend on the choice of standard (and reference) state. For all components of solid and liquid mixtures, $r_{\mathrm{B}} \equiv x_{\mathrm{B}} / x^{\circ}$ ("symmetrical convention"), where $x_{\mathrm{B}}$ is the mole fraction, and $x^{\circ}=1$ at the "pure substance" standard state. In aqueous electrolyte ("unsymmetrical convention"), for the water-solvent $\mathrm{W}, r_{\mathrm{W}} \equiv x_{\mathrm{W}} / x^{\circ}$ and $x^{\mathrm{o}}=1$; for a solute $\mathrm{B}$, $r_{\mathrm{B}}=m_{\mathrm{B}} / m^{\circ}, m^{\circ}=1 \mathrm{~mol} \mathrm{~kg}^{-1}$ (molality scale; sometimes, $r_{\mathrm{B}}=c_{\mathrm{B}} / c^{\mathrm{o}}, c^{\mathrm{o}}=1 \mathrm{moldm}^{-3}$ is alternatively defined in the molarity scale).

The concept of standard state involves two aspects: composition (relative content) and ideality [22]. The state of species B with respect to ideality is described by the activity coefficient $\gamma_{\mathrm{B}} \cdot \gamma_{\mathrm{B}} \longrightarrow \gamma^{\text {id }}=1$ at arbitrarily chosen ideal conditions (reference state), to which the standard chemical potential $\mu_{\mathrm{B}}^{\mathrm{o}}$ is also referenced. The quantity $\Delta \mu_{\mathrm{B}}=R T \ln \gamma_{\mathrm{B}}$ is the difference in chemical potentials of $\mathrm{B}$ at the real and the ideal states. This thermodynamic framework can also be applied to adsorbed species using either the surface coverage fraction $\theta_{\mathrm{B}}$ or the surface density $\Gamma_{\mathrm{B}}$ concepts [22], as also has been done in the existing definitions of standard states [21,27].

In the surface coverage fraction $\theta_{\mathrm{B}}=n_{\mathrm{S}, \mathrm{B}} / n_{\Sigma}, n_{\mathrm{S}, \mathrm{B}}$ is the amount of adsorbed B (moles) and $n_{\sum}$ is the total amount of all interface species including free "sites" or $\equiv \mathrm{OH}$ groups. Adopting $\theta^{\circ}=1$ leads to a complete coverage standard state [28]; the relative content of a surface species is then $r_{\mathrm{S}, \mathrm{B}}=\theta_{\mathrm{B}}$ and the activity is $a_{\mathrm{S}, \mathrm{B}}=\theta_{\mathrm{B}} \gamma_{\mathrm{S}, \mathrm{B}}$. The question here is: which species should be included into the summation in $n_{\sum}$ when some surface groups cannot be properly defined? Usually, $n_{\Sigma}$ includes only those surface species that might be converted into B by surface (complexation) reactions, as in $2 \mathrm{p} K$ and $1 \mathrm{p} K$ SCMs [4,25]. In such models, "immobilized" sites, inner- or outer-sphere surface complexes are included into $n_{\Sigma}$, but diffuse layer counter-ions are not. In site-balance LMA SCMs, $\theta_{\mathrm{B}}$ is usually defined as $\theta_{\mathrm{B}}=n_{\mathrm{S}, \mathrm{B}} / n_{\mathrm{M}, \text { tot }}$, where $n_{\mathrm{M}, \text { tot }}$ is the total amount of binding sites in the surface monolayer. As shown in [3], in the nonelectrostatic case, this restricts the SCM to the competitive Langmuir isotherm.

An alternative concentration scale is the surface density $\Gamma_{\mathrm{B}}=n_{\mathrm{S}, \mathrm{B}} / A$, where $A=n_{\mathrm{S}} M_{\mathrm{S}} A_{\mathrm{S}}$ is the reactive surface area, $n_{\mathrm{S}}$ is the amount of the sorbent, $M_{\mathrm{S}}$ is its molar mass, and $A_{\mathrm{S}}$ is its specific surface area (in $\mathrm{m}^{2} \mathrm{~g}^{-1}$ ). The relative content and the activity of interface species are $r_{\mathrm{S}, \mathrm{B}}=$ $\Gamma_{\mathrm{B}} / \Gamma_{\mathrm{o}}$ and $a_{\mathrm{S}, \mathrm{B}}=\gamma_{\mathrm{S}, \mathrm{B}} \Gamma_{\mathrm{B}} / \Gamma_{\mathrm{o}}$, respectively. Several values of the standard (reference) surface density $\Gamma_{\mathrm{o}}$ (in $\mathrm{mol} \mathrm{m}^{-2}$ ): $3.84 \times 10^{-6}[1] ; 2 \times 10^{-5}[27] ; 1.66 \times 10^{-5}$ [21]; or 1.0 [22] have been suggested, which means that this value still has to be agreed upon. A practically convenient $\Gamma_{\mathrm{o}}$ value should be related to site densities on oxides (from $0.95 \times 10^{-5}$ to $3.31 \times 10^{-5} \mathrm{~mol} \mathrm{~m}^{-2}$ [29]) which are close to the density of water molecules in the planar surface monolayer ( $c a$. $\left.2 \times 10^{-5} \mathrm{~mol} \mathrm{~m}^{-2}[26]\right)$. 
Using $r_{\mathrm{S}, \mathrm{B}}=\Gamma_{\mathrm{B}} / \Gamma_{\mathrm{o}}$ as relative content might be difficult when the surface area $A$ cannot be clearly defined, e.g. because of surface roughness or microporosity, or when describing ion exchange in zeolites or clays [5]. In this case, the sorption mass density $q_{\mathrm{M}, \mathrm{B}}=n_{\mathrm{B}} / M_{\mathrm{S}}$ or the sorption volume density $q_{\mathrm{V}, \mathrm{B}}=n_{\mathrm{B}} / V_{\mathrm{S}}$ may be preferred ( $V_{\mathrm{S}}$ is the sorbent volume). Then, to define the relative content, a conventional value of standard-state sorption density $q_{\mathrm{M}}^{\circ}$ or $q_{\mathrm{v}}^{\circ}$ must be chosen. However, this topic goes beyond the present scope, which is limited only to consideration of surface density $\Gamma_{\mathrm{B}}$ (expressed also as the number density $N_{\mathrm{B}}=10^{-18} \Gamma_{\mathrm{B}} N_{\mathrm{A}}$ in $\mathrm{nm}^{-2}$, where $N_{\mathrm{A}}$ is the Avogadro's number). Surface density is used in describing basic phenomena such as adsorption of gases on solids at low pressures [12,30], or adsorption of dilute aqueous species on solids. The surface density (of charge) is used in the Gouy-Chapman equation in electrostatic SCMs.

It is important to realize that the relative content defined above as $r_{\mathrm{B}}=\Gamma_{\mathrm{B}} / \Gamma_{\mathrm{C}}$ is not identical to the surface coverage fraction $\theta_{\mathrm{B}}$ which alternatively can be defined as $\theta_{\mathrm{B}}=$ $\Gamma_{\mathrm{B}} / \Gamma_{\mathrm{C}}$. Here, the standard-state surface density $\Gamma_{\mathrm{o}}$ is conventionally taken the same for all solids and surfaces [26], whereas the site density parameter $\Gamma_{\mathrm{C}}$ is a property of the particular sorbent surface. Keeping this fundamental difference in mind, the ideal behavior of adsorbed species B close to infinite dilution can be described by a linear isotherm that involves $K_{\mathrm{S}, \mathrm{B}}, \Gamma_{\mathrm{B}}$ and $\Gamma_{\mathrm{o}}$, but not $\Gamma_{\mathrm{C}}$. Any non-ideal deviation from this linear isotherm becomes then a product of the electrostatic $\gamma_{\mathrm{E}, \mathrm{B}}$ (involves the surface charge density $\sigma$ ) and a non-electrostatic $\gamma_{\mathrm{s}, \mathrm{B}}$ (involves $\Gamma_{\mathrm{B}}$ and $\Gamma_{\mathrm{C}}$ but not $\Gamma_{\mathrm{o}}$ ) contributions.

The electrostatic term $\left(\gamma_{\mathrm{E}, \mathrm{B}}\right)$ is commonly used in SCMs in triple layer (TL), basic Stern (BS), constant capacitance (CC), diffuse double layer (DL), and other models of the electrical double layer (EDL) [4,31]. According to Kallay et al. [22], the EDL correction term $z_{\mathrm{B}} F \varphi$ comprises the difference $\left(\Delta \mu_{\mathrm{E}, \mathrm{B}}=z_{\mathrm{B}} F \varphi\right)$ between the chemical potential of a surface species in a real and in an ideal (uncharged surface) states. Conversely, this term describes the impact of a mean electric field created by all charged surface species [24], and can be viewed as an electrostatic activity coefficient $\gamma_{\mathrm{E}, \mathrm{B}}=\exp \left[z_{\mathrm{B}} F \varphi /(R T)\right]\left(z_{\mathrm{B}}\right.$ is the charge number of adsorbed $\mathrm{B}, \varphi$ is the relative electrostatic potential on the surface plane of interest, and $F$ is the Faraday constant). The relative potential $\varphi$ of the EDL plane is a function of the charge density $\sigma$ and, optionally, electrostatic potentials on other planes and the capacitance density parameter(s). This topic is well discussed in the literature [4,31], and there is no need to consider it in more detail here. Non-electrostatic SCMs are used with success to describe sorption of hazardous cations on oxides [16] and clays [9]. The present paper is focused on the non-electrostatic $\gamma_{\mathrm{S}, \mathrm{B}}$ contribution to chemical potentials, unrecognized even in recent seminal papers $[21,22,28]$. In SCMs based on site balances, these contributions must be different from that in SCMs without site balance constraints. This obscure topic has been traditionally circumvented by assuming $\gamma_{\mathrm{S}, \mathrm{B}}$ to "equal unity" or to "cancel out" in the LMA expressions for adsorption reactions $[1,21]$. One reason might be that $\gamma_{\mathrm{S}, \mathrm{B}}$ and $\gamma_{\mathrm{E}, \mathrm{B}}$ contributions cannot be distinguished in titration data without making ad hoc extra-thermodynamic assumptions related to the definition of EDL electrostatic terms [24]. Another reason might be that activity coefficients of components in a mixed phase cannot be quantified if standard/reference state conventions are not well established [32].

\section{Non-ideality in non-electrostatic site-binding models}

\subsection{Linear adsorption at low coverage}

As follows from theory of adsorption [12,30], at very low pressure of a gaseous sorbate B with relatively high binding energy (i.e. large residence time) on the solid surface, the probability for B to stick to a surface site is very close to unity, while the probability of B to stick to an already adsorbed B molecule is near zero. This applies also to adsorption of dilute aqueous ions on mineral surfaces (the molality $m_{\mathrm{B}}$ is then used instead of pressure). The isotherm of such adsorption, described by the reaction $\mathrm{B}($ bulk $)=\mathrm{B}$ (surface), is linear, as long as the adsorbed density $\Gamma_{\mathrm{B}}$ is small:

$$
\Gamma_{\mathrm{B}}=K_{\mathrm{S}, \mathrm{B}}^{\prime} m_{\mathrm{B}} .
$$

Using the standard-state density $\Gamma_{\mathrm{o}}$ and the standard-state molality $m^{\circ}$, the relative content $r_{\mathrm{S}, \mathrm{B}}$ is expressed as

$$
r_{\mathrm{S}, \mathrm{B}}=\frac{\Gamma_{\mathrm{B}}}{\Gamma_{\mathrm{o}}}=K_{\mathrm{S}, \mathrm{B}} \frac{m_{\mathrm{B}}}{m^{\mathrm{o}}} \gamma_{\mathrm{B}},
$$

or $a_{\mathrm{S}, \mathrm{B}}=K_{\mathrm{S}, \mathrm{B}} a_{\mathrm{B}}$, where $K_{\mathrm{S}, \mathrm{B}}$ is the equilibrium constant of the reaction $\mathrm{B}(\mathrm{aq}) \longleftrightarrow \mathrm{B}(\mathrm{ads})$. This linear isotherm Eq. (3) describes the ideal adsorption behavior close to the "infinite surface dilution" $\left(\gamma_{\mathrm{S}, \mathrm{B}} \longrightarrow 1\right)$, consistent with the "infinite dilution" in bulk aqueous electrolyte $\left(\gamma_{\mathrm{B}} \longrightarrow 1\right)$. It holds also when different species B1, B2, ... are adsorbed on the same kind of sites at low surface coverage.

\subsection{Saturation of sites in the surface monolayer}

At higher concentrations of the sorbate $\mathrm{B}$, after $\Gamma_{\mathrm{B}}$ molecules per unit area have been adsorbed, the density of unoccupied sites is $\Gamma_{\mathrm{C}}-\Gamma_{\mathrm{B}}$, and the sticking probability is

$$
\frac{\Gamma_{\mathrm{C}}-\Gamma_{\mathrm{B}}}{\Gamma_{\mathrm{C}}}=1-\frac{\Gamma_{\mathrm{B}}}{\Gamma_{\mathrm{C}}}=1-\theta_{\mathrm{B}} .
$$

At significant surface coverage $\left(1-\theta_{\mathrm{B}}<1\right)$, Eq. (3) takes a more general form:

$$
\frac{\Gamma_{\mathrm{B}}}{\Gamma_{\mathrm{o}}}=K_{\mathrm{S}, \mathrm{B}} \frac{m_{\mathrm{B}}}{m^{\mathrm{o}}} \gamma_{\mathrm{B}}\left(1-\theta_{\mathrm{B}}\right)
$$

or

$$
r_{\mathrm{S}, \mathrm{B}}\left(1-\theta_{\mathrm{B}}\right)^{-1}=K_{\mathrm{S}, \mathrm{B}} a_{\mathrm{B}}
$$

Clearly, the term $\left(1-\theta_{\mathrm{B}}\right)^{-1}$ is equivalent to a non-electrostatic activity coefficient $\gamma_{\mathrm{S}, \mathrm{B}}$. Because the activity of the surface-bound species B is $a_{\mathrm{S}, \mathrm{B}}=K_{\mathrm{S}, \mathrm{B}} a_{\mathrm{B}}=r_{\mathrm{S}, \mathrm{B}} \gamma_{\mathrm{S}, \mathrm{B}}$, the $\gamma_{\mathrm{S}, \mathrm{B}}$ term can be expressed as

$$
\gamma_{\mathrm{L}, \mathrm{B}}=\frac{1}{1-\theta_{\mathrm{B}}}=\frac{\Gamma_{\mathrm{C}}}{\Gamma_{\mathrm{C}}-\Gamma_{\mathrm{B}}} .
$$




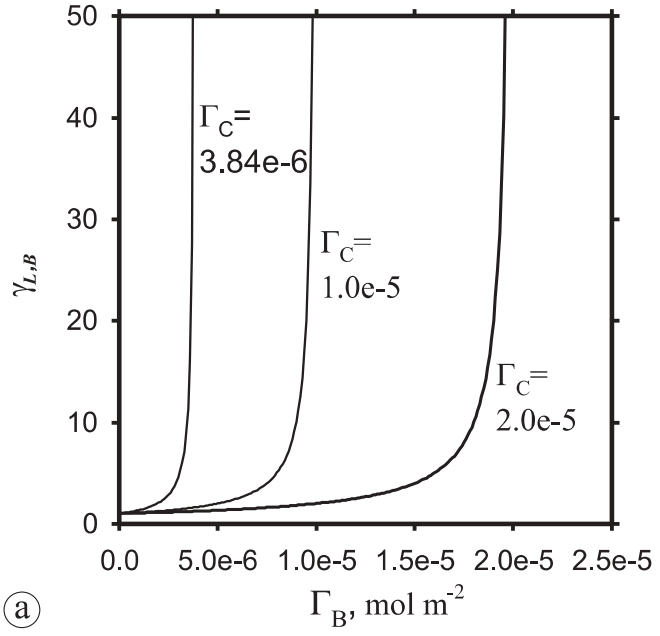

and will be called surface activity coefficient term (SACT). As seen on Fig. 1a, it becomes insignificant $\left(\gamma_{\mathrm{L}, \mathrm{B}}<1.11\right)$ at $\Gamma_{\mathrm{B}}<0.1 \Gamma_{\mathrm{C}}$. In Eqs. (3) and (4), the standard state parameter $\Gamma_{\mathrm{o}}$ is involved only in the $r_{\mathrm{S}, \mathrm{B}}$ term, while the site density parameter $\Gamma_{\mathrm{C}}$ is used only in the $\gamma_{\mathrm{L}, \mathrm{B}}$ term. Thus, when the equilibrium constant value $K_{\mathrm{S}, \mathrm{B}}$ is given, the "surface saturation" behavior specific for a given site type on a particular solid surface can be described using only the SACT Eq. (5). The equilibrium $K_{\mathrm{S}, \mathrm{B}}$ is referenced to infinite dilution by $\gamma_{\mathrm{B}}$ and $\gamma_{\mathrm{L}, \mathrm{B}}$ terms, and the $K_{\mathrm{S}, \mathrm{B}}$ value depends on $\Gamma_{\mathrm{o}}$, but not on $\Gamma_{\mathrm{C}}$. The adsorption isotherm of B can now be obtained by combining Eq. (4) and Eq. (5):

$$
\Gamma_{\mathrm{B}}=\frac{\Gamma_{\mathrm{o}} K_{\mathrm{S}, \mathrm{B}} a_{\mathrm{B}} \Gamma_{\mathrm{C}}}{\Gamma_{\mathrm{o}} K_{\mathrm{S}, \mathrm{B}} a_{\mathrm{B}}+\Gamma_{\mathrm{C}}}
$$

At fixed $K_{\mathrm{S}, \mathrm{B}}$, such isotherms deviate in response to different $\Gamma_{\mathrm{C}}$ parameters only at larger activities $a_{\mathrm{B}}$ (middle- and lowermost curves on Fig. 1b). At fixed $\Gamma_{\mathrm{C}}$ and at small $a_{\mathrm{B}}$, the isotherms will follow parallel linear slopes for different values of the $\Gamma_{\mathrm{o}} K_{\mathrm{S}, \mathrm{B}}$ product (top and middle curves on Fig. 1b).

The mathematical form of Eq. (6) resembles that of the classic Langmuir isotherm which, however, cannot distinguish between the standard-state surface density $\Gamma_{\mathrm{o}}$ and the site density $\Gamma_{\mathrm{C}}$. Indeed, substituting $\Gamma_{\mathrm{o}}$ by $\Gamma_{\mathrm{C}}$ in Eq. (6) and re-arranging, one has $\Gamma_{\mathrm{B}} / \Gamma_{\mathrm{C}}=K_{\mathrm{S}, \mathrm{B}} a_{\mathrm{B}}\left(1-\Gamma_{\mathrm{B}} / \Gamma_{\mathrm{C}}\right)$. Since $\Gamma_{\mathrm{B}} / \Gamma_{\mathrm{C}}$ is nothing else than the surface coverage fraction $\theta_{\mathrm{B}}$, one gets further $K_{\mathrm{S}, \mathrm{B}} a_{\mathrm{B}}=\theta_{\mathrm{B}} /\left(1-\theta_{\mathrm{B}}\right)$, which has exactly the form of non-competitive Langmuir isotherm. Therefore, the derivation of Eqs. (4) and (5) leads to a generalized Langmuir isotherm Eq. (6) with both the standard-state density $\Gamma_{\mathrm{o}}$ and the site density $\Gamma_{\mathrm{C}}$ parameters. But only $\Gamma_{\mathrm{C}}$ is involved in $\gamma_{\mathrm{L}, \mathrm{B}}$ (Eq. (5)) which, hence, can be called a noncompetitive Langmuir SACT.

The same reasoning as above leads to a SACT equation for the competitive adsorption of different monodentate species on the same kind of surface sites. The only additional assumption is that the adsorbate molecule $B_{j}$ of $\mathrm{j}$-th kind can stick to a free surface site and not to any already bound adsorbate molecule. The sticking probability will then be $\left(\Gamma_{\mathrm{C}}-\Gamma_{\Sigma}\right) / \Gamma_{\mathrm{C}}=1-\theta_{\Sigma}$, where $\Gamma_{\Sigma}=\sum_{\mathrm{j}} \Gamma_{\mathrm{j}}$ is the total density of adsorbed species of all kinds, and $\theta_{\Sigma}=\Gamma_{\Sigma} / \Gamma_{\mathrm{C}}$ is their total coverage fraction. The SACT $\gamma_{\mathrm{L}}$, the activity $a_{\mathrm{S}, \mathrm{j}}$, and the isotherm of species $\mathrm{B}_{\mathrm{j}}$ then become

$$
\begin{aligned}
\gamma_{\mathrm{L}} & =\left(1-\theta_{\Sigma}\right)^{-1}=\frac{\Gamma_{\mathrm{C}}}{\Gamma_{\mathrm{C}}-\Gamma_{\Sigma}} \\
a_{\mathrm{S}, \mathrm{j}} & =K_{\mathrm{S}, \mathrm{j}} a_{\mathrm{j}}=\frac{\Gamma_{\mathrm{j}}}{\Gamma_{\mathrm{o}}} \gamma_{\mathrm{L}} \\
\Gamma_{\mathrm{j}} & =\Gamma_{\mathrm{o}} K_{\mathrm{S}, \mathrm{j}} a_{\mathrm{j}} \frac{\Gamma_{\mathrm{C}}-\Gamma_{\Sigma}}{\Gamma_{\mathrm{C}}}
\end{aligned}
$$

As follows from Eq. (7), in equilibrium, all surface species competitively bound to the same kind of sites must have the same $\gamma_{\mathrm{L}}$ value because of the common $\Gamma_{\Sigma}$ value.

\subsection{Langmuir isotherm in site-balance SCMs}

The Langmuir isotherm equation for a monodentate adsorbed species B is usually written as

$$
K_{\mathrm{L}, \mathrm{B}} m_{\mathrm{B}}=\frac{\theta_{\mathrm{B}}}{1-\theta_{\mathrm{B}}},
$$

where $K_{\mathrm{L}, \mathrm{B}}$ is the apparent binding constant; $m_{\mathrm{B}}$ is the aqueous molality of adsorbate $\mathrm{B}$; and $\theta_{\mathrm{B}}$ is fractional surface coverage of adsorbed B. Eq. (10) is usually explained via reactions like $\equiv \mathrm{H}_{2} \mathrm{O}+\mathrm{B}$ (bulk) $\Longleftrightarrow \equiv \mathrm{B}+\mathrm{H}_{2} \mathrm{O}$ or $\equiv+$ $\mathrm{B}$ (bulk) $\Longleftrightarrow \equiv \mathrm{B}$, where "”" denotes the surface site [3]. It is assumed that each adsorbed molecule B occupies one binding site (monodentate adsorption on a homogeneous planar surface); adsorption is terminated at a site density $\Gamma_{\mathrm{C}}$ upon completion of a monolayer; no lateral interactions between the adsorbed B molecules take place. By balancing such site-binding reactions, it is easy to demonstrate ([3], Chapt. 10) that each site mole balance constraint in traditional LMA SCMs (e.g. in FITEQL codes) produces an effect identical to the Langmuir isotherm ( Eq. (10)). As shown above, by setting $\Gamma_{\mathrm{o}}=\Gamma_{\mathrm{C}}$, Eq. (10) can be re-written in adsorbed density scale as

$$
K_{\mathrm{L}, \mathrm{B}} m_{\mathrm{B}}=\frac{\Gamma_{\mathrm{B}}}{\Gamma_{\mathrm{C}}} \frac{\Gamma_{\mathrm{B}}}{\Gamma_{\mathrm{C}}-\Gamma_{\mathrm{B}}},
$$

also in the competitive case using intrinsic adsorption constants $K_{\mathrm{B}}^{\mathrm{int}}$ instead of $K_{\mathrm{L}, \mathrm{j}}$ :

$$
K_{\mathrm{B}}^{\text {int }} a_{\mathrm{B}}=\frac{\Gamma_{\mathrm{B}}}{\Gamma_{\mathrm{C}}} \frac{\Gamma_{\mathrm{B}}}{\Gamma_{\mathrm{C}}-\Gamma_{\Sigma}},
$$


This competitive Langmuir isotherm is built into each single-site monodentate-binding LMA SCM based on the site mole balance. Comparison of Eqs. (11) and (6) shows that the deviation from linear adsorption in the classic Langmuir isotherm is a specific case of the more general Eqs. (6) or (9) if and only if $\Gamma_{\mathrm{o}}=\Gamma_{\mathrm{C}}$. Therefore, the site-balance based SCMs cannot reproduce curves like the middle one on Fig. $1 \mathrm{~b}$ without a simultaneous change of $\Gamma_{\mathrm{o}}=\Gamma_{\mathrm{C}}$ and $K_{\mathrm{j}}^{\mathrm{int}}$. In other words, in such SCMs, different values of the site density parameter $\Gamma_{\mathrm{C}}$ result in different standard states for adsorbed species. This explains why the fitted $K_{\mathrm{j}}^{\text {int }}$ values depend on $\Gamma_{\mathrm{C}}$ (or $q_{\mathrm{C}}$ ) [33] and can be compared only after re-scaling to a common (standard-state) surface density $\Gamma_{\mathrm{o}}[21,26]$. Conversely, site-balance-based SCMs are not really convenient for reproducing physically reasonable isotherms (e.g. BET, Frumkin, Freundlich, QCA) other than the Langmuir, especially for multi-layer adsorption.

\subsection{Method of recovering SACTs from adsorption isotherms}

Let us assume that a non-electrostatic adsorption isotherm equation consists of ideal and non-ideal parts. As seen from previous analysis, these parts can be separated, if: (1) the relative adsorbed amount is defined as $r_{\mathrm{B}}=\Gamma_{\mathrm{B}} / \Gamma_{\mathrm{o}}$; (2) the standard-state density is considered to be different from the complete-coverage site density parameter $\left(\Gamma_{\mathrm{o}} \neq \Gamma_{\mathrm{C}}\right)$; and (3) the reference state is set at infinite dilution, and the form of the ideal isotherm is known. Condition (3) can be satisfied in two ways: either assuming linear adsorption as ideal behavior (Eq. (3)), or assuming a (competitive) Langmuir curve (Eq. (12)) as ideal behavior in site-balance based SCMs. However, the latter assumption implies site balance and contradicts conditions (1) and (2). Hence, the linear ideal adsorption case is preferable; it also makes the SCM site balance constraints obsolete by replacing them with SACTs.

A method for splitting the Langmuir adsorption isotherm equation into ideal (linear isotherm) and non-ideal (SACT) parts can be deduced by comparing Eqs. (11), (4) and (5). For instance, the SACT Eq. (5) can be obtained from the Langmuir isotherm (Eq. (11)) by multiplying both sides by $\left(m^{\circ} \Gamma_{\mathrm{C}}\right) /\left(m^{\circ} \Gamma_{\mathrm{o}}\right)$ and the left side by $\gamma_{\mathrm{B}} / \gamma_{\mathrm{B}}$, and re-arranging. This yields $K_{\mathrm{L}, \mathrm{B}}\left(m^{\circ} \Gamma_{\mathrm{C}}\right) /\left(\gamma_{\mathrm{B}} \Gamma_{\mathrm{o}}\right) m_{\mathrm{B}} / m^{\circ} \gamma_{\mathrm{B}}=$ $\left(\Gamma_{\mathrm{B}} / \Gamma_{\mathrm{o}}\right) \Gamma_{\mathrm{C}} /\left(\Gamma_{\mathrm{C}}-\Gamma_{\mathrm{B}}\right)$. Further, denoting $m_{\mathrm{B}} / m^{0} \gamma_{\mathrm{B}}=a_{\mathrm{B}}$, $\Gamma_{\mathrm{B}} / \Gamma_{\mathrm{o}}=r_{\mathrm{S}, \mathrm{B}}$, and $\Gamma_{\mathrm{C}} /\left(\Gamma_{\mathrm{C}}-\Gamma_{\mathrm{B}}\right)=\gamma_{\mathrm{S}, \mathrm{B}}$, one obtains $K_{\mathrm{L}, \mathrm{B}}\left(m^{\circ} \Gamma_{\mathrm{C}}\right) /\left(\gamma_{\mathrm{B}} \Gamma_{\mathrm{o}}\right) a_{\mathrm{B}}=r_{\mathrm{S}, \mathrm{B}} \gamma_{\mathrm{L}, \mathrm{B}}$. Finally, denoting $K_{\mathrm{L}, \mathrm{B}}$ $\left(m^{\circ} \Gamma_{\mathrm{C}}\right)\left(\gamma_{\mathrm{B}} \Gamma_{\mathrm{o}}\right)=K_{\mathrm{S}, \mathrm{B}}$ results in Eq. (5). Hence, the splitting of Langmuir isotherm into ideal and non-ideal parts consists in applying the relation Eq. (13)

$$
K_{\mathrm{L}, \mathrm{B}}=K_{\mathrm{S}, \mathrm{B}} \frac{\gamma_{\mathrm{B}} \Gamma_{\mathrm{o}}}{m^{\mathrm{o}} \Gamma_{\mathrm{C}}}
$$

to Eq. (11) (or to Eq. (12) in the case of competitive Langmuir isotherm). Eq. (13) connects the Langmuir apparent constant $K_{\mathrm{L}, \mathrm{B}}$ to the standard-state constant $K_{\mathrm{S}, \mathrm{B}}$. Since the intrinsic adsorption constant $K_{\mathrm{B}}^{\text {int }}$ (used in LMA SCMs) is already referenced to the standard-state molality (by $m^{\circ}$ ) and aqueous infinite dilution (by $\gamma_{\mathrm{B}}$ ), the relation between $K_{\mathrm{B}}^{\mathrm{int}}$ and $K_{\mathrm{S}, \mathrm{B}}$ is even simpler:

$$
K_{\mathrm{B}}^{\mathrm{int}}=K_{\mathrm{S}, \mathrm{B}} \frac{\Gamma_{\mathrm{o}}}{\Gamma_{\mathrm{C}}}
$$

From Eq. (14), it follows that $K_{\mathrm{B}}^{\text {int }}$ for reactions like $\equiv \mathrm{H}_{2} \mathrm{O}+\mathrm{B} \Longleftrightarrow \mathrm{B}+\mathrm{H}_{2} \mathrm{O}$ or $\equiv+\mathrm{B} \Longleftrightarrow \equiv \mathrm{B}$ must depend on the underlying $\Gamma_{\mathrm{C}}$ parameter. Relations like Eq. (14) are shown [26] to hold only if the activity of surface sites or $\equiv \mathrm{H}_{2} \mathrm{O}$ or $\equiv \mathrm{OH}$ groups is constant and independent of surface coverage. For the above reactions, Eq. (14) can be used also for converting the $K_{\mathrm{B}}^{\text {int }}$ value from one site density parameter $\left(\Gamma_{\mathrm{o}}\right)$ to another $\left(\Gamma_{\mathrm{C}}\right)$. However, for species $\mathrm{A}$ and $\mathrm{B}$ in "ion exchange" reactions like $\equiv \mathrm{A}+\mathrm{B} \Longleftrightarrow \equiv \mathrm{B}+\mathrm{A}$, the equilibrium constant value should not depend on $\Gamma_{\mathrm{C}}$ or $\Gamma_{\mathrm{o}}$ because

$$
K_{\mathrm{AB}}^{\mathrm{int}}=\frac{K_{\mathrm{B}}^{\mathrm{int}}}{K_{\mathrm{A}}^{\mathrm{int}}}=K_{\mathrm{S}, \mathrm{AB}}=\frac{K_{\mathrm{S}, \mathrm{B}}}{K_{\mathrm{S}, \mathrm{A}}}
$$

where the terms $\Gamma_{\mathrm{o}} / \Gamma_{\mathrm{C}}$ from Eq. (14) just cancel out.

\subsection{Obtaining SACT for poly-dentate surface binding}

In site-balance SCMs, according to Benjamin [28], it is difficult to model the bi-dentate or, in general, the $n$-dentate binding which must obey isotherms other than those of the monodentate Langmuir type (Eqs. (11), (12)). Let us apply our new method to the QCA isotherm for $n$-dentate surface binding [20], based on the following assumptions: the adsorbate $\mathrm{B}^{(\mathrm{n})}$ is an " $n$-dentate" molecule occupying exactly $n$ sites; it does not obstruct other empty sites; it is immobile while on the surface, and does not interact with any other $\mathrm{B}^{(\mathrm{n})}$ molecule except via "hard" interactions that prevent the multiple occupation of sites. The bulk phase is either a gas or a liquid; the adsorbate coverage is always less than a monolayer; the mixing of different adsorbates is excluded. For our purposes, the QCA isotherm [20] can be written as

$$
K_{\mathrm{L}, \mathrm{B}}^{(n)} m_{\mathrm{B}}=\theta_{\mathrm{B}}^{(n)} \frac{\left(1-\theta_{\mathrm{B}}^{(n)}\right)^{n-1}}{\left(1-n \theta_{\mathrm{B}}^{(n)}\right)^{n}}, 1 \leq n \leq 4,
$$

where $\theta_{\mathrm{B}}^{(n)}=\Gamma_{\mathrm{B}}^{(n)} / \Gamma_{\mathrm{C}}$ and $\Gamma_{\mathrm{B}}^{(n)}$ is the surface density of $\mathrm{B}^{(\mathrm{n})}$ (in mol m${ }^{-2}$ ). Eq. (15) reduces to the Langmuir isotherm (Eq. (10)) at $n=1$. Application of Eq. (13) to Eq. (15) yields immediately

$$
\begin{aligned}
K_{\mathrm{S}, \mathrm{B}} a_{\mathrm{B}} & =a_{\mathrm{S}, \mathrm{B}}=\frac{\Gamma_{\mathrm{B}}^{(n)}}{\Gamma_{\mathrm{o}}} \gamma_{\mathrm{L}, \mathrm{B}}^{(n)} \\
\gamma_{\mathrm{L}, \mathrm{B}}^{(n)} & =\frac{\left(1-\theta_{\mathrm{B}}^{(n)}\right)^{n-1}}{\left(1-n \theta_{\mathrm{B}}^{(n)}\right)^{n}}=\frac{\Gamma_{\mathrm{C}}\left(\Gamma_{\mathrm{C}}-\Gamma_{\mathrm{B}}^{(n)}\right)^{n-1}}{\left(\Gamma_{\mathrm{C}}-n \Gamma_{\mathrm{B}}^{(n)}\right)^{n}} .
\end{aligned}
$$

As expected, the function $\gamma_{\mathrm{L}, \mathrm{B}}^{(n)}$ reduces to the Langmuir SACT (Eq. (5)) at $n=1$.

Fig. 2 shows that plots of the function $\gamma_{\mathrm{L}, \mathrm{B}}^{(n)}$ at different values of $n$ exhibit correct behavior at infinite surface dilution, with $\gamma_{\mathrm{L}, \mathrm{B}}^{(n)} \longrightarrow 1$ regardless of $n$. Asymptotic lines approached by $\gamma_{\mathrm{L}, \mathrm{B}}^{(n)}$ curves at increasing $\Gamma_{\mathrm{B}}^{(n)}$ are located at $\Gamma_{\mathrm{C}} / n$ positions. The site density $\Gamma_{\mathrm{C}}$ is involved in Eq. (17) only. Further work is required to extend Eq. (17) to competitive adsorption of species with the same or different $n$. 


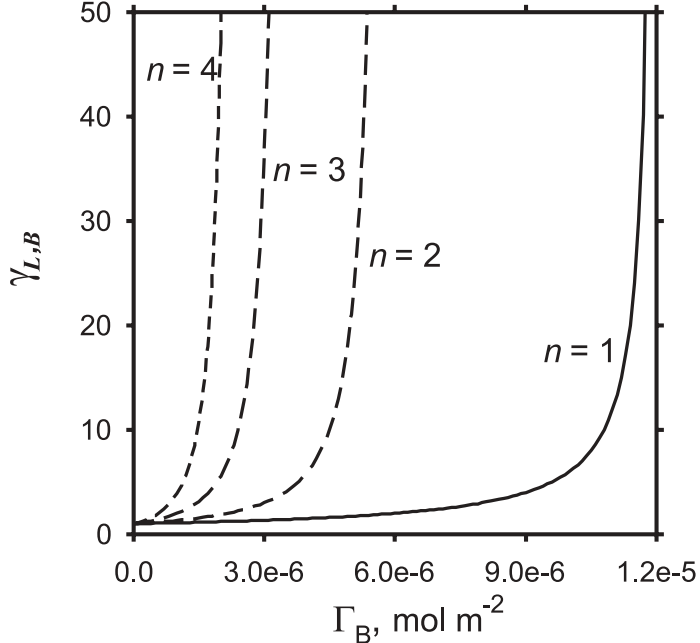

Fig. 2. Shape of the QCA SACT Eq. (17) at $\Gamma_{\mathrm{C}}=1.2 \times 10^{-5} \mathrm{~mol} \mathrm{~m}^{-2}$ and various "dentateness" $n$.

\subsection{Obtaining SACT from Frumkin isotherm}

The Frumkin isotherm $[34,35]$ contains a correction term for the "soft" lateral interactions between the adsorbed species:

$$
K_{\mathrm{F}, \mathrm{B}} m_{\mathrm{B}}=\frac{\theta_{\mathrm{B}}}{1-\theta_{\mathrm{B}}} \exp \left(-2 \alpha_{\mathrm{F}} \theta_{\mathrm{B}}\right)
$$

where $K_{\mathrm{F}, \mathrm{B}}$ is the apparent adsorption constant, and $\alpha_{\mathrm{F}}$ is the interaction parameter; negative values of $\alpha_{\mathrm{F}}$ mean repulsion (the usual case). There is a considerable interest in this macroscopic model due to its theoretical connection to molecular adsorption mechanisms and its efficiency in describing proton and metal adsorption data on oxides [36, 37]. Interestingly, the exponential Frumkin term has almost the same mathematical form as the "constant capacitance" EDL correction term [34].

By applying the analog of Eq. (13), $K_{\mathrm{F}, \mathrm{B}}=K_{\mathrm{S}, \mathrm{B}}\left(\gamma_{\mathrm{B}} \Gamma_{\mathrm{o}}\right) /$ $\left(m^{\circ} \Gamma_{\mathrm{C}}\right)$, to Eq. (18), and re-arranging, we obtain

$$
\begin{aligned}
& K_{\mathrm{S}, \mathrm{B}} a_{\mathrm{B}}=a_{\mathrm{S}, \mathrm{B}}=\frac{\Gamma_{\mathrm{B}}}{\Gamma_{\mathrm{o}}} \gamma_{\mathrm{F}, \mathrm{B}} \\
& \gamma_{\mathrm{F}, \mathrm{B}}=\frac{\Gamma_{\mathrm{C}}}{\Gamma_{\mathrm{C}}-\Gamma_{\mathrm{B}}} \exp \left(-2 \alpha_{\mathrm{F}} \frac{\Gamma_{\mathrm{B}}}{\Gamma_{\mathrm{C}}}\right)
\end{aligned}
$$

Eq. (20) is the Frumkin SACT, with a behavior shown on Fig. 3a. Setting $\alpha_{\mathrm{F}}=0$ reduces it to the non-competitive Langmuir SACT (Eq. (5)). By combining Eq. (19) and Eq. (20), a generalized Frumkin isotherm for monodentate species is obtained:

$$
\Gamma_{\mathrm{B}}=\frac{\Gamma_{\mathrm{o}} K_{\mathrm{S}, \mathrm{B}} a_{\mathrm{B}} \Gamma_{\mathrm{C}}}{\Gamma_{\mathrm{o}} K_{\mathrm{S}, \mathrm{B}} a_{\mathrm{B}}+\Gamma_{\mathrm{C}} \exp \left(-2 \alpha_{\mathrm{F}} \frac{\Gamma_{\mathrm{B}}}{\Gamma_{\mathrm{C}}}\right)} .
$$

As seen on Fig. $3 b$, at very small $a_{\mathrm{B}}$ (near infinite dilution), Frumkin isotherms reduce to the ideal linear isotherm, $\Gamma_{\mathrm{B}}=\Gamma_{\mathrm{o}} K_{\mathrm{S}, \mathrm{B}} a_{\mathrm{B}}$. Around $\theta_{\mathrm{B}}=0.5$, the effect of Frumkin SACT with negative $\alpha_{\mathrm{F}}$ is similar to that of bi- or tri-dentate QCA SACT. Further work should extend Eq. (20) to competitive adsorption of different aqueous species.

\section{Implementation issues and modeling examples}

The activity of adsorbed species $a_{\mathrm{S}, \mathrm{B}}=\exp \left[\left(\mu_{\mathrm{S}, \mathrm{B}}-\mu_{\mathrm{S}, \mathrm{B}}^{\mathrm{o}}\right) /\right.$ $(R T)]$ is represented here as a product of the surface relative amount $\left(\Gamma_{\mathrm{B}} / \Gamma_{\mathrm{o}}\right)$, the SACT $\left(\gamma_{\mathrm{S}, \mathrm{B}}\right)$, and the electrostatic term $\left(\gamma_{\mathrm{E}, \mathrm{B}}\right)$. The ideal (linear) adsorption occurs when $\left(\gamma_{\mathrm{S}, \mathrm{B}}\right)=1$ and $\left(\gamma_{\mathrm{E}, \mathrm{B}}\right)=1$. For the first time, the SACT expressions for $\left(\gamma_{\mathrm{S}, \mathrm{B}}\right)$ have been derived for monolayer adsorption described by Langmuir (also competitive), QCA (1- to 4-dentate binding) and Frumkin (lateral interactions) non-electrostatic isotherms. These SACTs must reproduce site saturation effects without site-balance constraints. Here, some implementation issues will be tackled to show how SACT expressions may influence the SCM behavior in modeling some literature data for $\mathrm{U}^{\mathrm{VI}}$ adsorption on goethite.

As well known, the site-balance LMA SCMs include not a sorbent as such, but only the total amount of its binding sites $n_{\mathrm{Mtot}}=\Gamma_{\mathrm{C}} A$, where $A$ is the surface area (in $\mathrm{m}^{2}$ ) and $\Gamma_{\mathrm{C}}$ is the site density. The surface speciation is computed using the $n_{\mathrm{M} \text { tot }}$ balance and the mass action equations [3,38], optionally with electrostatic corrections by the EDL model of choice [4]. The standard states for surface species implied in site-balance LMA SCMs were considered by Sverjensky [21]. Adsorption heterogeneity is represented by allocating surface complexes to several different site types and introducing the related site-balance constraints, as done e.g. in the MUSIC approach [25].
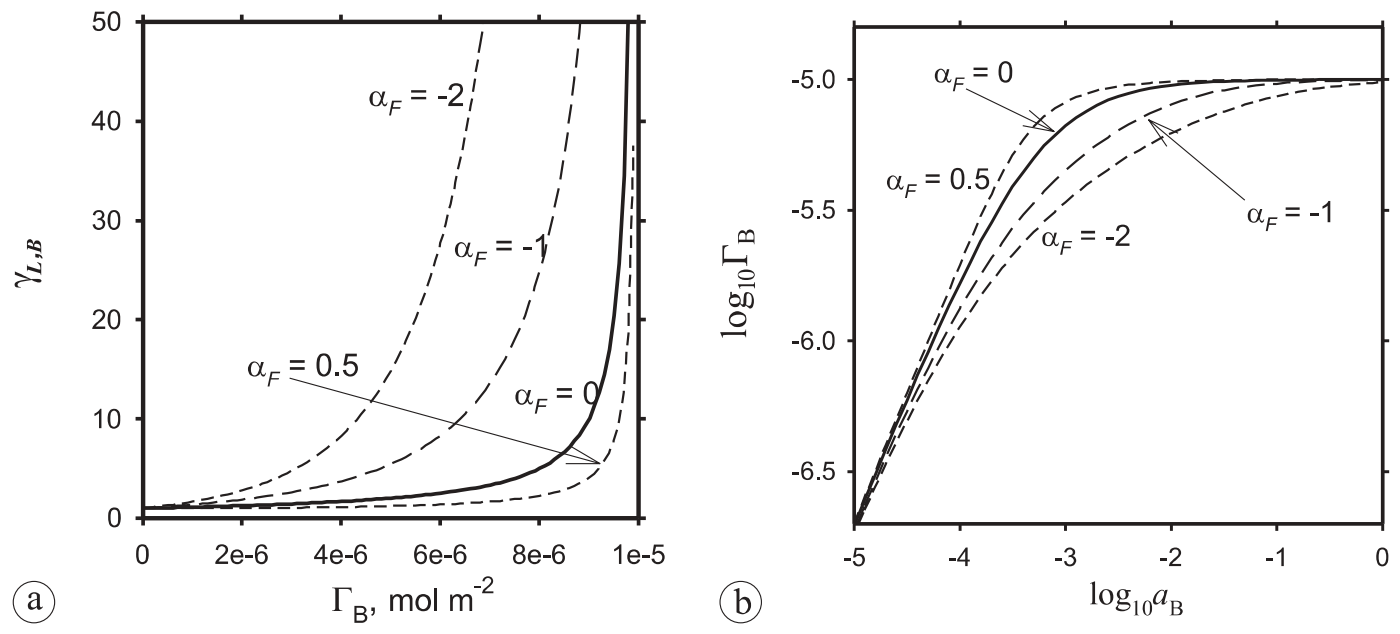

Fig. 3. Frumkin SACT functions computed at various interaction parameters $\alpha_{\mathrm{F}}, \Gamma_{\mathrm{C}}=10^{-5}$ $\mathrm{mol} \mathrm{m}{ }^{-2}$, and $K_{\mathrm{S}, \mathrm{B}}=10^{3}$. (a): plots of Eq. (20); (b): generalized Frumkin isotherms (Eq. (21)). 
SCMs without site balances were implemented using SACT equations and EDL electrostatic corrections in the GEM algorithm which solves for the aqueous - solidsolution - adsorption speciation in the whole system [26, 27]. GEM SCMs use the standard state with one mole of interface species occupying at $\Gamma_{\mathrm{o}}=2 \times 10^{-5} \mathrm{~mol} \mathrm{~m}^{-2}$ all surface of one mole of the sorbent of specific surface area $A_{\mathrm{o}}=$ $5 \times 10^{5} \mathrm{~m}^{2} \mathrm{~mol}^{-1}$ suspended in $1 \mathrm{~kg} \mathrm{H}_{2} \mathrm{O}$ at 1 bar pressure and defined temperature. The standard chemical potential $\mu_{\mathrm{S}, \mathrm{B}}^{\mathrm{o}}$ is referenced to a hypothetical "infinite surface dilution" at zero surface charge and potential for a surface complex $\mathrm{B}$, and to a complete coverage state at $\Gamma_{\mathrm{o}}$ for the surface water (solvent) or $\equiv \mathrm{OH}$ group. In the GEMS-PSI code (http://les.web.psi.ch/Software/GEMS-PSI/), the SACT Eqs. $(5,7,17,20)$ are calculated between iterations of the GEM algorithm together with aqueous activity coefficients. This code (version 2.1) with built-in thermodynamic database [39] has been used in all examples below. Eqs. (5, $7,17,20)$ supersede the surface activity terms (SAT [27]) applied in earlier versions of GEMS-PSI code.

Literature data on adsorption isotherms of aqueous inorganic ions on oxide surfaces show Langmuir-like patterns when measured at constant $\mathrm{pH}$, relatively high total ion, and relatively low solid concentrations [14, 16, 17, 40,41], i.e. at medium to high coverage. Giammar and Hering [40] determined the partitioning of uranyl $\mathrm{UO}_{2}{ }^{2+}$ between an aqueous solution (with $0.1 \mathrm{M} \mathrm{NaNO}_{3}$, open to the air) and $0.1-0.5 \mathrm{~g} \mathrm{~L}^{-1}$ synthetic goethite $\left(A_{\mathrm{S}}=42.2 \mathrm{~m}^{2} \mathrm{~g}^{-1}\right)$ at $\mathrm{pH}=6$ and temperature $22 \pm 2{ }^{\circ} \mathrm{C}$ at relatively high $\mathrm{U}^{\mathrm{VI}}$ total concentrations. At short reaction times (several hours), these authors observed a metastable adsorption of uranyl on goethite described by the Langmuir isotherm

$$
\Gamma_{\mathrm{U}}=\frac{\Gamma_{\mathrm{C}} K_{\mathrm{L}, \mathrm{U}} c_{\mathrm{U}}}{1+K_{\mathrm{L}, \mathrm{U}} c_{\mathrm{U}}}
$$

with fitted parameters $K_{\mathrm{L}, \mathrm{U}}=0.653 \mu \mathrm{M}^{-1}$ and $\Gamma_{\mathrm{C}}=$ $2.71 \mu \mathrm{mol} \mathrm{m}{ }^{-2}$ (see Eq. (1), Fig. 1 in [40]). The apparent binding constant $K_{\mathrm{L}, \mathrm{U}}\left(\log _{10} K_{\mathrm{L}, \mathrm{U}}=-6.185\right)$ seems to be referenced to the $1.0 \mathrm{M}$ concentration scale and a standard state at $\Gamma_{(\mathrm{o})}=2.71 \mu \mathrm{mol} \mathrm{m}^{-2}\left(N_{(\mathrm{o})}=1.632 \mathrm{~nm}^{-2}\right)$. As follows from Eq. (13), a conversion of $K_{\mathrm{L}, \mathrm{U}}$ to an equilibrium constant $K_{\mathrm{S}, \mathrm{U}}$ referenced to $\Gamma_{\mathrm{o}}=20 \mu \mathrm{mol} \mathrm{m}{ }^{-2}$ would require the knowledge of: aqueous speciation of uranium at the conditions of experiment; stoichiometry and "dentateness" of uranyl surface complex; and the site density $\Gamma_{\mathrm{C}}$ parameter. Because of the complexity of $\mathrm{U}^{\mathrm{VI}}$ aqueous speciation, the computer-aided modeling is necessary.

\subsection{GEM TL SCM for uranyl on goethite}

The system has been modeled using the triple layer (TL) model [42] for goethite, merged with our earlier uranium aqueous - surface speciation GEM model [26] and new SACT Eqs. (7, 17, 20) applied as activity coefficients together with the TL electrostatic terms. This model differs from the LMA TL model of Villalobos et al. [42,43] in that the site-balance constraints were replaced by SACTs and the surface species were defined in the elemental stoichiometry. Our complete model (Table 1), which can be called "GEM TL SCM", performs well on the potentiometric titration and carbonate adsorption data [42,43] (model fits not shown here), as well as on the uranyl adsorption data [42] (one example is shown on Fig. 4a). On the basis of low observed maximum densities of adsorbed $\mathrm{U}^{\mathrm{VI}}$ [40], it was assumed that $\mathrm{U}^{\mathrm{VI}}$ binds on a specific site type 2 of density $\Gamma_{\mathrm{C}, 2}$, whereas all other species (protonated and deprotonated $\mathrm{OH}$ groups, carbonate and electrolyte surface complexes) bind to the site type 1 of much greater site density $\Gamma_{\mathrm{C}, 1}$ (see Table 1 ). The use of "binuclear" [42] adsorbed $\mathrm{U}^{\mathrm{VI}}$ species reflects the spectroscopic evidence that uranyl binds on Fe (hydr)oxide surfaces by two equatorial oxygens, in form of a doubly coordinated $\gg \mathrm{OUO}_{2}{ }^{0}$ (UL) neutral surface complex plus a charged ternary complex $\gg \mathrm{OUO}_{2}\left(\mathrm{CO}_{3}\right)_{2}{ }^{4-}$ (ULC) in the presence of $\mathrm{CO}_{2}$.

As seen on Fig. 4a, the ULC species should prevail at low $\mathrm{U}^{\mathrm{VI}}$ coverage and $\mathrm{pH}>5.5$. However, at higher coverage (Fig. 4b), another UL species prevails at $\mathrm{pH}<8.3$, although dissolved aqueous uranyl [ $\left.\mathrm{U}_{\mathrm{aq}}^{\mathrm{VI}}\right]$ is still below $1 \times 10^{-6} \mathrm{M}$. Conversely, in the experimental range of data [40], at $\mathrm{U}_{\mathrm{aq}}^{\mathrm{VI}}$. between 0.1 and $40 \mu \mathrm{M}$, the neutral UL complex should be predominant in the $\mathrm{U}^{\mathrm{IV}}$ surface speciation at $\mathrm{pH}$ around 6 . Trial modeling of $\mathrm{U}^{\mathrm{VI}}$ adsorption isotherms (conditions as in experiments [40], $T=25^{\circ} \mathrm{C}$ ) has shown that the surface density curve for ternary ULC complex reaches a plateau at $0.6 \mu \mathrm{M}$ of dissolved $\mathrm{U}^{\mathrm{VI}}$, and at higher concentrations remains flat at $0.3 \pm 0.03 \mathrm{~nm}^{-2}\left(22 \pm 2 \mu \mathrm{mol} \mathrm{g}^{-1}\right)$, probably limited by constant atmospheric $p_{\mathrm{CO}_{2}}$. For the UL species, $\log _{10} K_{\mathrm{S}, \mathrm{UL}}=-6.53\left(\right.$ good for modeling the $\mathrm{U}^{\mathrm{VI}} \mathrm{pH}$ adsorption edge data [42]) was found to be $c a$. $1 \mathrm{pK}$ unit too strong for modeling the $\mathrm{U}^{\mathrm{VI}}$ adsorption isotherm data [40]. Nevertheless, the UL species with $\log _{10} K_{\mathrm{S}, \mathrm{UL}}=-7.58$ was chosen to represent metastable and/or oligomeric $\mathrm{U}^{\mathrm{VI}}$ surface complexes in modeling runs described below. Formation of oligomeric adsorbed $\mathrm{U}^{\mathrm{VI}}$ species is thought to occur on (hydr)oxide surfaces at higher dissolved uranyl concentrations $[26,44]$.

\subsection{Modeling the $\mathrm{U}^{\mathrm{VI}}$ adsorption isotherm using QCA SACT}

Objectives of the modeling were: (i) to test model sensitivity to Eqs. (7) and (17) when $K_{\mathrm{S}, \mathrm{UL}}$ of the UL species and the density parameter for uranyl-specific sites $\Gamma_{\mathrm{C}_{2}}$ were adjusted simultaneously; (ii) to test the model sensitivity to Eq. (17) when the $\Gamma_{\mathrm{C}, 2}$ parameter was fixed; and (iii) to check how the model fits can be improved if Eq. (20) is used instead of Eq. (7). Parameters controlled in modeling runs are summarized in Table 2. As the main interest was the model sensitivity to non-electrostatic SACTs and not the fitted adsorption equilibrium constants, the goodness of fit was estimated visually, without applying least-squares regression procedures and criteria like SOS/DF in the FITEQL code. Because of the metastability of $\mathrm{U}^{\mathrm{VI}}$ adsorption data (as shown in [40], at reaction times longer than several hours, the dissolved $U^{\mathrm{VI}}$ decreased possibly due to precipitation of the uranyl oxide hydrate minerals), the adjusted values of $K_{\mathrm{S}, \mathrm{UL}}$ from Table 2 may not be directly applicable to other data measured at far smaller uranyl surface loadings or at longer reaction times.

In the run 1- $n 1-0$ (Fig. 5), the $\mathrm{U}^{\mathrm{VI}}$ adsorption isotherm data [40] could be described well assuming that both uranyl surface species are monodentate and compete (Eq. (7)) for type 2 sites of density $\Gamma_{\mathrm{C}, 2}=3.49 \mu \mathrm{mol} \mathrm{m}^{-2}\left(N_{\mathrm{C}, 2}=\right.$ 
Table 1. $2 p \mathrm{~K}_{A}$ GEM TL SCM parameters for goethite (including carbonate and $\mathrm{U}^{\mathrm{VI}}$ adsorption).

\begin{tabular}{|c|c|c|c|c|c|c|}
\hline $\begin{array}{l}\text { Species } \\
\text { (reaction) }\end{array}$ & Site type & 0 plane charge & $\beta$ plane charge & $G_{298}^{\mathrm{o}} \mathrm{kJ} \mathrm{mol}^{-1}$ & $\log K_{\mathrm{S}, 298}$ & $\begin{array}{c}\log K^{\text {int }} \\
\text { [ref] }\end{array}$ \\
\hline $\begin{array}{l}>\mathrm{O}_{0.5} \mathrm{H}_{2}^{+} \\
\text {(1) }\end{array}$ & 1 & 1 & 0 & -167.93 & -6.90 & $\begin{array}{r}-6.9 \\
{[43]}\end{array}$ \\
\hline $\begin{array}{l}>\mathrm{O}_{0.5}{ }^{-} \\
(2)\end{array}$ & 1 & -1 & 0 & -66.33 & -10.90 & $\begin{array}{r}-10.9 \\
{[43]}\end{array}$ \\
\hline $\begin{array}{l}>\mathrm{O}_{0.5} \mathrm{H}_{2}^{+} \mathrm{NO}_{3}^{-} \\
\text {(3) }\end{array}$ & 1 & 1 & -1 & -285.17 & -8.01 & $\begin{array}{l}-8.088 \\
{[43]}\end{array}$ \\
\hline $\begin{array}{l}>\mathrm{O}_{0.5}{ }^{-} \mathrm{Na}^{+} \\
\text {(4) }\end{array}$ & 1 & -1 & 1 & -332.84 & -10.09 & $\begin{array}{c}-10.01 \\
{[43]}\end{array}$ \\
\hline $\begin{array}{l}>\mathrm{O}_{0.5} \mathrm{COO}^{-} \\
(5)\end{array}$ & 1 & -0.2 & -0.8 & -491.73 & 12.68 & $\begin{array}{l}12.76 \\
{[43]}\end{array}$ \\
\hline $\begin{array}{l}>\mathrm{O}_{0.5} \mathrm{COONa}^{0} \\
\text { (6) }\end{array}$ & 1 & 0 & 0 & -751.55 & 12.32 & $\begin{array}{l}12.404 \\
{[43]}\end{array}$ \\
\hline $\begin{array}{l}\gg \mathrm{OUO}_{2}\left(\mathrm{CO}_{3}\right)_{2}{ }^{4-}(\mathrm{ULC}) \\
\text { (7) }\end{array}$ & 2 & -2 & -2 & $-2307.06^{a}$ & $7.25^{a}$ & $\begin{array}{l}10.57 \\
{[42]}\end{array}$ \\
\hline$\underset{(8)}{\gg \mathrm{OUO}_{2}^{0}(\mathrm{UL})}$ & 2 & 0 & 0 & $-1172.44^{a}$ & $-6.53^{a}$ & $\begin{array}{c}-4.71 \\
{[42]}\end{array}$ \\
\hline $\begin{array}{l}\gg \mathrm{OUO}_{2}{ }^{0}(\mathrm{~m})(\mathrm{UL}) \\
(8)\end{array}$ & 2 & 0 & 0 & $-1166.44^{b}$ & $-7.58^{b}$ & [this work] \\
\hline
\end{tabular}

Other TL SCM parameters: $\mathrm{C}_{1}=1.0 \mathrm{Fm}^{-2} ; \mathrm{C}_{2}=0.2 \mathrm{Fm}^{-2} ; \Gamma_{\mathrm{C}, 1}=16.61 \mathrm{molm}^{-2}\left(N_{\mathrm{C}, 1}=10 \mathrm{~nm}^{-2}\right.$, site type 1$), \Gamma_{\mathrm{o}}=20.0 \mu \mathrm{mol} \mathrm{m}{ }^{-2}\left(N_{\mathrm{o}}=\right.$ $12.05 \mathrm{~nm}^{-2}$ ). For inner-sphere $\mathrm{U}^{\mathrm{VI}}$ surface species (site type 2), the site density parameter $\Gamma_{\mathrm{C}, 2}=6.0 \mu \mathrm{mol} \mathrm{m}^{-2}\left(N_{\mathrm{C} .2}=3.61 \mathrm{~nm}^{-2}\right)$ is taken as for singly- or doubly- coordinated oxygens [47]. The SACT (Eq. (7)) was used for all species on site type 1 . Reactions: $(0) 0.5 \mathrm{H}_{2} \mathrm{O} \Longleftrightarrow$ $>\mathrm{O}_{0.5} \mathrm{H}^{0}\left(\log _{10} K=1.74436, G_{298}^{\mathrm{o}}\left(>\mathrm{O}_{0.5} \mathrm{H}^{0}\right)=-128.55 \mathrm{~kJ} \mathrm{~mol}^{-1}[26]\right) ; \quad$ (1) $>\mathrm{O}_{0.5} \mathrm{H}_{2}{ }^{+} \Longleftrightarrow>\mathrm{O}_{0.5} \mathrm{H}^{0}+\mathrm{H}^{+} ;(2)>\mathrm{O}_{0.5} \mathrm{H}^{0} \Longleftrightarrow>\mathrm{O}_{0.5}{ }^{-}+\mathrm{H}^{+}$; (3) $>\mathrm{O}_{0.5} \mathrm{H}_{2}{ }^{+} \mathrm{NO}_{3}{ }^{-} \Longleftrightarrow>\mathrm{O}_{0.5} \mathrm{H}^{0}+\mathrm{H}^{+}+\mathrm{NO}_{3}{ }^{-}$; (4) $>\mathrm{O}_{0.5} \mathrm{H}^{0}+\mathrm{Na}^{+} \Longleftrightarrow>\mathrm{O}_{0.5}{ }^{-} \mathrm{Na}^{+}+\mathrm{H}^{+}$; (5) $>\mathrm{O}_{0.5} \mathrm{H}^{0}+\mathrm{CO}_{3}{ }^{2-}+\mathrm{H}^{+} \Longleftrightarrow>\mathrm{O}_{0.5} \mathrm{COO}^{-}+\mathrm{H}_{2} \mathrm{O}$; (6) $>\mathrm{O}_{0.5} \mathrm{H}^{0}+\mathrm{CO}_{3}{ }^{2-}+\mathrm{Na}^{+}+\mathrm{H}^{+} \Longleftrightarrow>\mathrm{O}_{0.5} \mathrm{COONa}^{0}+\mathrm{H}_{2} \mathrm{O}$; (7) $2>\mathrm{O}_{0.5} \mathrm{H}^{0}+\mathrm{UO}_{2}{ }^{2+}+2 \mathrm{CO}_{3}{ }^{2-} \Longleftrightarrow \gg \mathrm{OUO}_{2}\left(\mathrm{CO}_{3}\right)_{2}{ }^{4-}+2 \mathrm{H}^{+}$; (8) $2>\mathrm{O}_{0.5} \mathrm{H}^{0}+$ $\mathrm{UO}_{2}{ }^{2+} \Longleftrightarrow \gg \mathrm{OUO}_{2}{ }^{0}+2 \mathrm{H}^{+}$.

a: fitted to experimental data [42] because the LMA constant given there for "binuclear" surface complex was too strong for GEM model;

b: adjusted to reproduce data [40] in the run 1-n $1-0$ using $\Gamma_{\mathrm{C}, 2}=3.49 \mu \mathrm{mol} \mathrm{m}^{-2}\left(N_{\mathrm{C}, 2}=2.1 \mathrm{~nm}^{-2}\right)$, with SACT Eq. (7) applied for site types 1 and 2 separately.
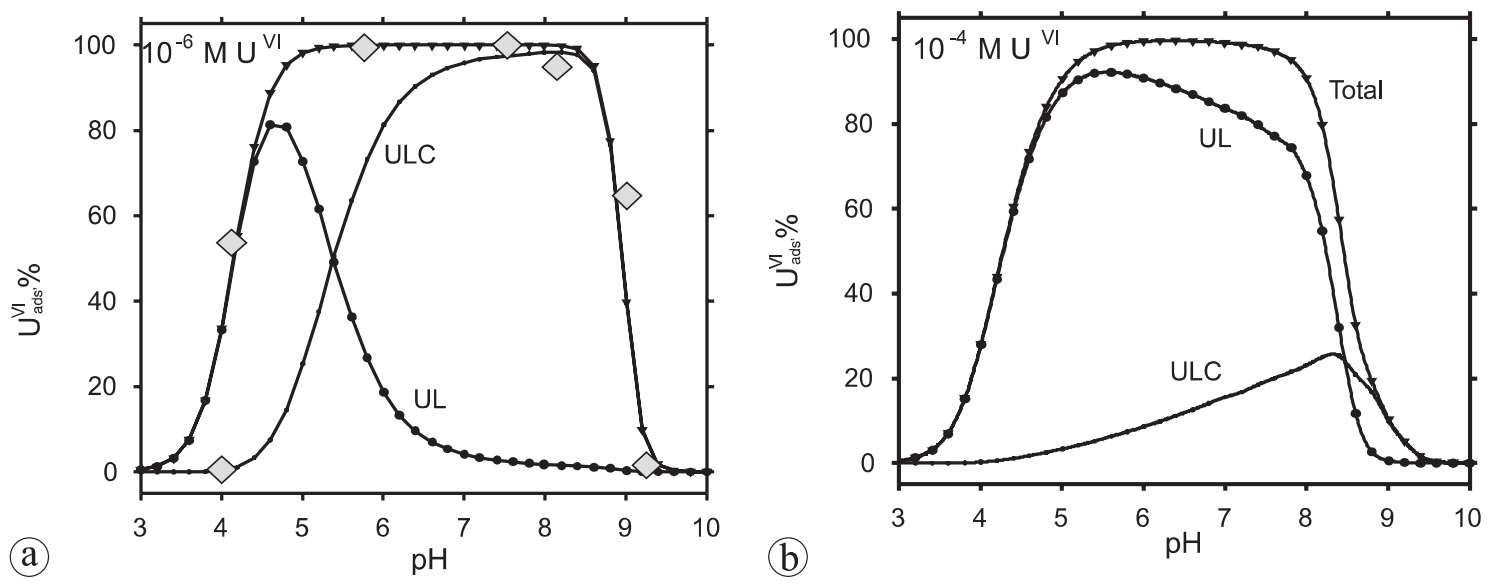

Fig. 4. Modeled $\mathrm{pH}$ edges and surface speciation of $\mathrm{U}^{\mathrm{VI}}$ on $1 \mathrm{~g} \mathrm{~L}^{-1}$ goethite $\left(45 \mathrm{~m}^{2} \mathrm{~g}^{-1}\right)$ under $\mathrm{N}_{2}-\mathrm{O}_{2}-\mathrm{CO}_{2}$ atmosphere $\left(p \mathrm{CO}_{2}=32 \mathrm{~Pa}\right)$ and $\Gamma_{\mathrm{C}, 2}=$ $2.66 \times 10^{-6} \mathrm{~mol} \mathrm{~m}^{-2}\left(N_{\mathrm{C} 2}=1.6 \mathrm{~nm}^{-2}\right)$ for the inner-sphere $\mathrm{U}^{\mathrm{VI}}$ adsorption site type at a total uranium load of $1 \times 10^{-6} \mathrm{M}(\mathbf{a})$ and $1 \times 10^{-4} \mathrm{M}(\mathbf{b})$. "UL" denotes $\gg \mathrm{OUO}_{2}{ }^{0}$; "ULC" denotes the $\gg \mathrm{OUO}_{2}\left(\mathrm{CO}_{3}\right)_{2}{ }^{4-}$ surface species. Diamonds refer to the experimental data [42].

$2.1 \mathrm{~nm}^{-2}$, Table 2). With this (adjusted) $\Gamma_{\mathrm{C}, 2}$ value, the best visual fits in the whole region were obtained (Fig. 5).

On Figs. 5, 6 and 7, model plots on the right side are zoomed fragments of plots on the left side, provided just in order to make the model fits in the low $\mathrm{U}^{\mathrm{VI}}$ surface coverage region better visible. It has been found that the form of modeled isotherm at $\left[\mathrm{U}_{\mathrm{aq}}^{\mathrm{VI}}\right]>0.5 \mu \mathrm{M}$ did not change when the ternary uranyl species ULC was excluded and $\log _{10} K_{\text {S,UL }}$ was corrected to -7.48 . Hence, only the UL surface complex was included in further calculations (Figs. 6, 7). In one series (Fig. 6a), $\log _{10} K_{\mathrm{S}, \mathrm{UL}}=-7.48$ was kept constant and the $\Gamma_{\mathrm{C}, 2}$ parameter has been adjusted for different "dentateness" $n$. In another series (Fig. 6b), the site density $\Gamma_{\mathrm{C}, 2}$ was set to "proportional" values $n \cdot 2.1 \mathrm{~nm}^{-2}$, and $\log _{10} K_{\mathrm{S}, \mathrm{UL}}$ values have been adjusted to improve the fit at $\mathrm{U}_{\mathrm{aq}}^{\mathrm{VI}}>10 \mu \mathrm{M}$ at different $n=1,2,3$ or 4 .

From this modeling exercise, we see that SACTs such as Eq. (5), Eq. (7) or Eq. (17) can indeed replace the site-balance constraints. If the site density $\Gamma_{\mathrm{C}, 2}$ is taken as a freely adjustable parameter, then almost equally good SCM fits (Fig. 6a) can be obtained using the Langmuir, 2, 3, and 4-dentate QCA corrections with the same value of $K_{\mathrm{S}, \mathrm{UL}}$. 
Table 2. Summary of parameters set or adjusted in model runs (for other parameters, see Table 1).

\begin{tabular}{lccccccr}
\hline Run & $\log _{10} K_{\mathrm{S}, \mathrm{UL}}$ & $N_{\mathrm{C}, 2}$ & $n$ & Run & $\log _{10} K_{\mathrm{S}, \mathrm{UL}}$ & $N_{\mathrm{C}, 2}$ & $\alpha_{\mathrm{F}}$ \\
\hline $1-n 1-1$, & -7.48 & 2.1 & 1 & $2-F-1$ & -7.13 & 1.81 & 0.0 \\
$1-n 1-2$ & & & & & & & \\
$1-n 2-1$ & -7.48 & 5.6 & 2 & $2-F-2$ & -6.73 & 1.81 & -0.5 \\
$1-n 3-1$ & -7.48 & 12 & 3 & $2-F-3$ & -7.58 & 1.81 & 0.5 \\
$1-n 4-1$ & -7.48 & 20 & 4 & $3-F-1$ & -7.53 & 2.7 & 0.0 \\
$1-n 2-2$ & -7.13 & 4.2 & 2 & $3-F-2$ & -7.15 & 2.7 & -1.0 \\
$1-n 3-2$ & -6.58 & 6.3 & 3 & $3-F-3$ & -7.68 & 2.7 & 0.5 \\
$1-n 4-2$ & -6.08 & 8.4 & 4 & $3-F-4$ & -7.93 & 2.7 & 0.5 \\
\hline
\end{tabular}

$K_{\mathrm{S}, \mathrm{UL}}$ values correspond to the reaction $2>\mathrm{O}_{0.5} \mathrm{H}^{0}+\mathrm{UO}_{2}{ }^{2+}=\gg \mathrm{OUO}_{2}{ }^{0}+2 \mathrm{H}^{+}$; the site density parameter $N_{\mathrm{C}, 2}$ is given in $\mathrm{nm}^{-2}$ units.
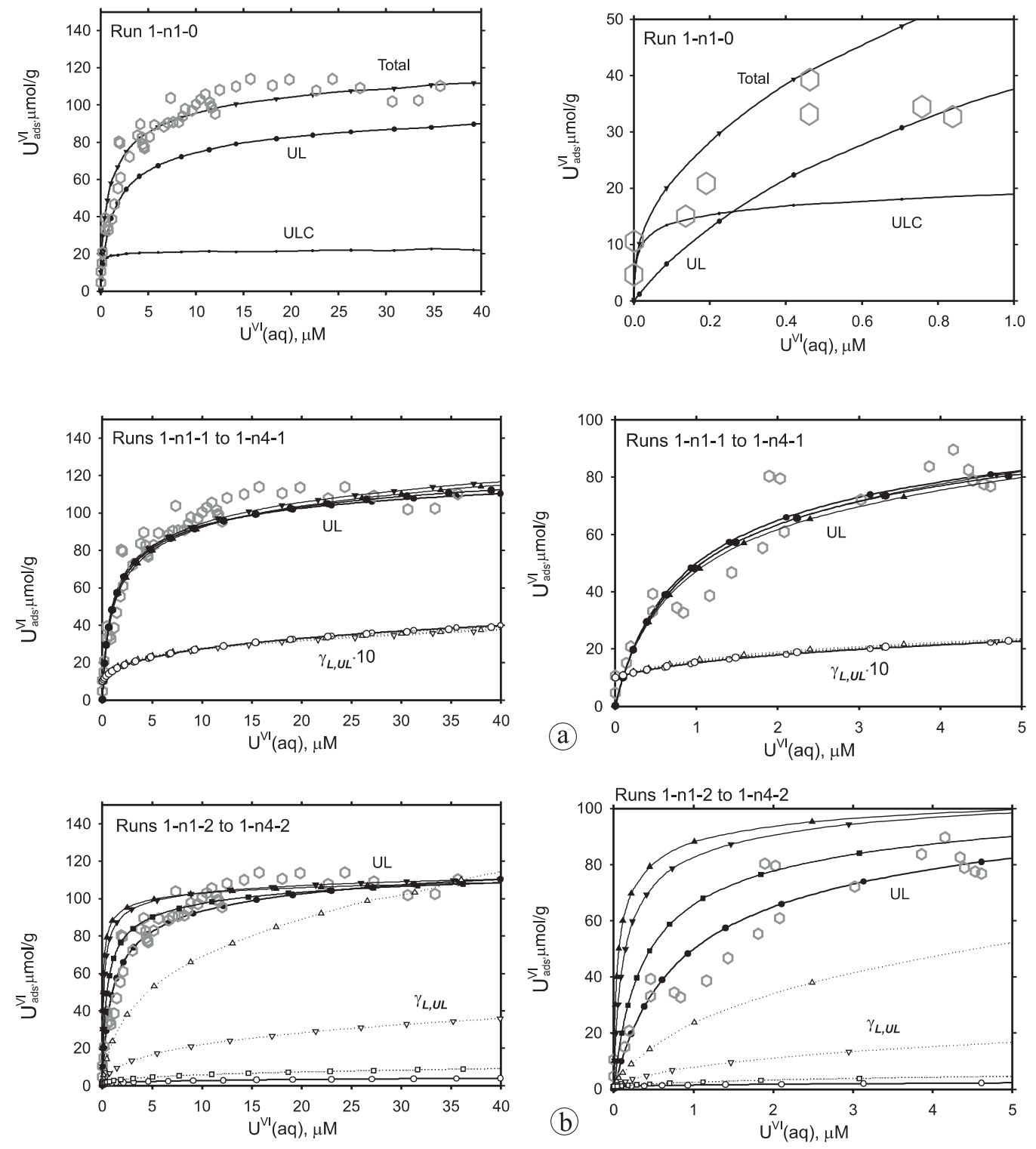

Fig. 6. Modeled $\mathrm{U}^{\mathrm{VI}}$ adsorption isotherms using QCA SACT (Eq. (17)) at $n=1$ (Langmuir, lines with small circles); $n=2$ (squares); $n=$ 3 (triangles down); $n=4$ (triangles up): (a): using the same $K_{\mathrm{S}, \mathrm{UL}}$ and adjusted $N_{\mathrm{C}, 2}$; (b): using "proportional" $\quad N_{\mathrm{C}, 2}=n \cdot 2.1 \mathrm{~nm}^{-2}$ site densities and adjusted values of $K_{\text {S,UL }}$ (see Table 2). Open hexagons: experimen-

tal data [40].

Fig. 5. $\mathrm{U}^{\mathrm{VI}}$ adsorption isogons) modeled using GEM TL SCM parameters from Table 1 (run 1-n1-0). On this on the right side are zoomed parts of plots on the left side, provided for better inspecconcentration range.

This observation brings us back to the old idea $[45,46]$ that using the site density $\Gamma_{\mathrm{C}}$ as an adjustable model parameter makes the SCMs, at best, semi-empirical, and jeopardizes any mechanistic conclusions from model fits. However, putting even primitive "proportional" constraints on $\Gamma_{\mathrm{C}, 2}$ (Fig. 6b) makes the situation dramatically different. The SCM curve shapes become quite sensitive to $\Gamma_{\mathrm{C}, 2}$ value, require significant adjustments of $K_{\mathrm{S}, \mathrm{UL}}$, and result in much greater "non-ideality" with SACT $\gamma_{\mathrm{L}, \mathrm{UL}}^{(n)}$ values up to 100 and more.

\subsection{Modeling $\mathrm{U}^{\mathrm{VI}}$ adsorption with Frumkin SACT}

The QCA isotherm and Eq. (17) represent "hard" lateral interactions between immobile surface-bound species [20,28]. Alternatively, in the Frumkin isotherm and Eq. (20), lateral 

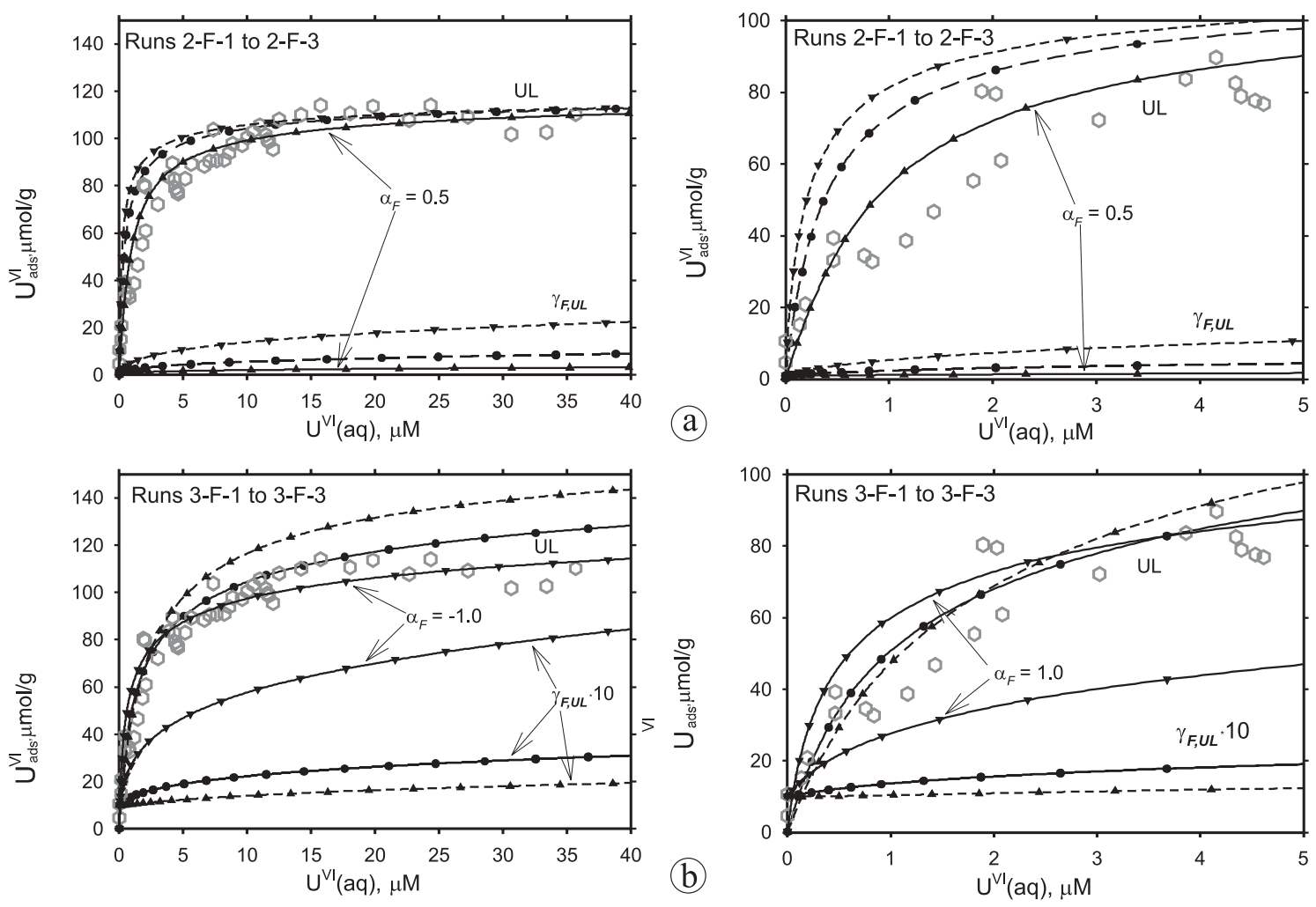

Fig. 7. Modeled $\mathrm{U}^{\mathrm{VI}}$ adsorption isotherms using the Frumkin SACT (Eq. (20)). (a): at constant $N_{\mathrm{C}, 2}=1.81 \mathrm{~nm}^{-2}$ (lines with small circles: $\alpha_{\mathrm{F}}=0$; triangles down: $\alpha_{\mathrm{F}}=-1.0$; triangles up: $\alpha_{\mathrm{F}}=0.5$, best fit). (b): at constant $N_{\mathrm{C}, 2}=2.7 \mathrm{~nm}^{-2}$ (lines with small circles: $\alpha_{\mathrm{F}}=0$; triangles down: $\alpha_{\mathrm{F}}=-1.0$; triangles up: $\alpha_{\mathrm{F}}=0.5$ ). Open hexagons: experimental data [40]. See Table 2 for adjusted $K_{\mathrm{S}, \mathrm{UL}}$ values.

interactions are accounted for in a "soft" way, via the $\alpha_{\mathrm{F}}$ parameter. To see the impact of Eq. (20) on the modeled adsorption isotherm, the binding was assumed monodentate, the site density $\Gamma_{\mathrm{C}, 2}$ has been fixed using the available crystallographic and spectroscopic data for goethite surfaces (see below), and the adjustable parameters were $K_{\mathrm{S}, \mathrm{UL}}$ and $\alpha_{\mathrm{F}}$.

Goethite particles exhibit mainly crystal planes (110) (90\% of surface) and (001) or (021) (10\%), on which singly-, doubly- and triply-coordinated oxygens are exposed with charges $-1 \frac{1}{2},-1$ and $-\frac{1}{2}$, respectively [25,47]. Singlyand triply-coordinated oxygen sites are considered protonreactive; for the whole goethite surface, the average density of singly-coordinated oxygens is taken as $3.61 \mathrm{~nm}^{-2}$, and that of triply-coordinated oxygens - as $2.7 \mathrm{~nm}^{-2}[47,48]$. It is not yet clear to which kind of surface sites the inner-sphere binding of uranyl ion occurs; there are three possibilities. One is that uranyl binds to a singly- and an adjacent triplycoordinated oxygen; such pairs having density $3.0 \mathrm{~nm}^{-2}$ are located on (110) planes and should have $N_{\mathrm{C}, 2}=2.7 \mathrm{~nm}^{-2}$ for the total goethite surface. Other variant is that uranyl binds to two adjacent singly-coordinated sites, which gives $N_{\mathrm{C}, 2}=1.81 \mathrm{~nm}^{-2}$ for the UL species (in the Frumkin model, we assume that one site of $3.61 \mathrm{~nm}^{-2}$ density consists of two adjacent $\mathrm{Fe}^{\mathrm{III}}-\mathrm{O}$ bonds). Finally, uranyl can bind to two doubly-coordinated oxygens (of the same density as singlycoordinated ones), which also gives $N_{\mathrm{C}, 2}=1.81 \mathrm{~nm}^{-2}$.

Interestingly, the maximum adsorbed density of $\mathrm{U}^{\mathrm{VI}}$ on goethite was found to be $2.71 \times 10^{-6} \mathrm{~mol} \mathrm{~m}^{-2}$ or $1.632 \mathrm{~nm}^{-2}$ [40], - only slightly less than the theoretical $N_{\mathrm{C}, 2}=1.81 \mathrm{~nm}^{-2}$. The first variant also seems to be supported by some atomistic modeling results [49]. So, we are left with two variants to try: (1) $N_{\mathrm{C}, 2}=1.81 \mathrm{~nm}^{-2}$ (UL species bound to pairs of doubly or singly-coordinated oxygens) and (2) $N_{\mathrm{C}, 2}=2.7 \mathrm{~nm}^{-2}$ (UL species bound to singly- and triply-coordinated oxygens). These density parameters were fixed in two model runs using the Frumkin SACT (Eq. (20)).

Variant 1 model runs with $N_{\mathrm{C}, 2}=1.81 \mathrm{~nm}^{-2}$ (Fig. 7a) show that the usage of $\alpha_{\mathrm{F}}=0$ (i.e. the Langmuir isotherm) provides, in general, a satisfactory fit, somewhat worse at $\left[\mathrm{U}_{\mathrm{aq}}^{\mathrm{VI}}\right]<5 \mu \mathrm{M}$. The Frumkin parameter $\alpha_{\mathrm{F}}=-0.5$ (lateral "repulsion") requires a much stronger $K_{\mathrm{S}, \mathrm{UL}}$, which leads to a significant SACT contribution $\left(\gamma_{\mathrm{F}, \mathrm{L}}>20\right)$ and makes the fit at $\left[\mathrm{U}_{\mathrm{aq}}^{\mathrm{VI}}\right]<5 \mu \mathrm{M}$ worse. However, setting a positive Frumkin parameter $\alpha_{\mathrm{F}}=0.5$ (lateral "attraction") and weakening $K_{\mathrm{S} \text {,UL }}$ results in almost perfect fit in the whole $\mathrm{U}_{\mathrm{aq}}^{\mathrm{VI}}$ range, with small $\gamma_{\mathrm{FUL}}<3$. Could this modeling result point to a tendency of formation of oligomeric uranyl surface species at high coverage on goethite surface?

In variant 2 model runs with $N_{\mathrm{C}, 2}=2.7 \mathrm{~nm}^{-2}$ (Fig. 7b), setting $\alpha_{\mathrm{F}}=0$ provides a good fit, except some overprediction at $\left[\mathrm{U}_{\mathrm{aq}}^{\mathrm{VI}}\right]>25 \mu \mathrm{M}$. The overall fit can be improved by setting negative $\alpha_{\mathrm{F}}$ values and taking stronger $K_{\mathrm{S}, \mathrm{UL}}$ at the same time, though the model curve is not very sensitive to this. For instance, $\alpha_{\mathrm{F}}=-1.0$ and $\log _{10} K_{\mathrm{S}, \mathrm{UL}}=-7.15$ provide a good fit in the whole range. However, positive values of $\alpha_{\mathrm{F}}$ (and much weaker $K_{\mathrm{S}, \mathrm{UL}}$ ) do not let the fit be good in the whole range at all. At $\alpha_{\mathrm{F}}=0.5$, the model fits the data at $\left[\mathrm{U}_{\mathrm{aq}}^{\mathrm{VI}}\right]<5 \mu \mathrm{M}$, but with a considerable over-prediction at higher coverage (Fig. 7b). Setting a weaker $K_{\mathrm{S}, \mathrm{UL}}$ to fit data at $\left[\mathrm{U}_{\mathrm{aq}}^{\mathrm{VI}}\right]>20 \mu \mathrm{M}$ results in a significant under-prediction at lower coverage (not shown). 


\section{Concluding remarks}

The modeling examples show that our new approach to thermodynamic modeling of surface complexation of ions (including actinides) on mineral-water interfaces is feasible in the whole range from low to high surface coverage. The differences between other SCMs and ours consist in expressing stoichiometries of surface species only in chemical elements and charge, and in replacing surface site balances by SACT equations. Due to this, our SCM approach (implemented in a GEMS-PSI equilibria solver) can reproduce not only the Langmuir, but also various other adsorption isotherms. In GEM SCMs, all the familiar TL, BS, CC, DL and other electrostatic terms $\left(\gamma_{\mathrm{E}, \mathrm{B}}\right)$ can be applied simultaneously with the SACT $\left(\gamma_{\mathrm{S}, \mathrm{B}}\right)$ corrections.

We suggest considering the ideal behavior of a surface species (B) as a linear isotherm only. Then, a nonelectrostatic adsorption isotherm equation of choice can be split into a linear part (involving the adsorption equilibrium constant $K_{\mathrm{S}, \mathrm{B}}$ referenced to infinite dilution), and a non-linear part - the SACT $\gamma_{\mathrm{S}, \mathrm{B}}$ (involving the site density $\Gamma_{\mathrm{C}}$ ). A simple method of such splitting (Eq. (13)) has been developed by deriving a SACT (Eqs. (5), (7)) from the Langmuir isotherm for the monolayer monodentate surface binding. Next, this method was used to obtain a SACT (Eq. (17)) for 1-, 2-, 3- and 4-dentate binding from the QCA isotherm, and further on, a SACT (Eq. (20)) derived from the Frumkin isotherm which accounts for "soft" lateral interactions between the surface-bound species. In GEM SCMs, these SACTs replace the previously suggested [27] not rigorous and less precise "surface activity terms" (SAT) (the impact of this replacement is evaluated elsewhere [50]).

In the non-electrostatic case, at a given equilibrium constant $K_{\mathrm{S}, \mathrm{B}}$ and site density $\Gamma_{\mathrm{C}}$ values, GEM SCMs with the Langmuir SACT (Eq. (5) or (7)) reproduce the adsorption curves that can be calculated in LMA SCM codes (e.g. FITEQL) from the surface site balance. This happens because any site balance constraint results in the same activityconcentration dependence as the Langmuir isotherm (see Eq. (11), (12)). It is easy to simulate other isotherms in GEM SCMs just by selecting other SACT expressions, but this may be difficult to do (especially for the multi-layer adsorption) in traditional site-balance LMA SCMs limited to competitive Langmuir isotherms. Can LMA SCMs be modified to work around this limitation?

This question is addressed rather to developers of LMA modeling codes, to which the author does not belong. Nevertheless, one simple solution can be imagined. In a LMA SCM, even in a multi-site one, one fictive site balance for all surface species must be retained, needed just to simulate linear isotherms as the ideal adsorption case. This fictive site balance must be based on a very large conventional standard-state surface density, e.g. $\Gamma_{\mathrm{o}}=1 \mathrm{~mol} \mathrm{~m}^{-2}$. Available intrinsic constants $K^{\text {int }}$ must be corrected to $\Gamma_{\mathrm{o}}$ beforehand using Eq. (14). Next, SACT Eqs. (5), (7), (17) or (20) together with their parameters $\left(\Gamma_{\mathrm{C}}, n, \alpha_{\mathrm{F}}\right)$ need to be properly assigned to surface complexes on different sites, and then iteratively calculated just as any activity coefficients during the progress of speciation calculations. This potential extension should bring three advantages. (i) Any fitted adsorption constant will be not intrinsic but an equilib- rium constant $K_{\mathrm{S}, \mathrm{B}}$ referenced to the standard-state surface density $\left(\Gamma_{\mathrm{o}}\right)$ and to the infinite dilution reference state; all such constants are intercomparable. (ii) LMA SCMs will become more flexible due to a gained ability to simulate not solely Langmuir, but other isotherms (QCA, Frumkin, BET, Freundlich, ...) as well. (iii) Problems associated with incorporation of $n$-dentate surface complexes will disappear because the "dentateness" is manifested only in the QCA SACT term, but not involved into the ideal isotherm and the definition of $K_{\mathrm{S}, \mathrm{B}}$.

Our method of splitting adsorption isotherms to ideal (linear) and non-ideal parts can and shall be applied to several other isotherms (BET, Freundlich, Tóth, ...) of interest for adsorption of radionuclides on MWIs or mineral-gas interfaces. For instance, the BET isotherm (cf. [30]) describes the transition from mono- to multi-layer adsorption up to surface condensation. Even though this isotherm is usually applied to gas adsorption on porous or particulate solids, there were attempts to use it for describing adsorption of transitional metals on (hydr)oxides [17, 18] in the form

$$
\Gamma_{\mathrm{M}}=\frac{\Gamma_{\mathrm{C}} b^{\prime} c_{\mathrm{M}}}{\left(c_{\mathrm{M}, \mathrm{sat}}-c_{\mathrm{M}}\right)\left[1+\left(b^{\prime}-1\right)\left(c_{\mathrm{M}} / c_{\mathrm{M}, \mathrm{sat}}\right)\right]},
$$

where $b^{\prime}=K_{\text {ads }}^{\prime} / K_{\mathrm{ppt}}, K_{\mathrm{ads}}^{\prime}$ and $K_{\mathrm{ppt}}$ are the equilibrium constants of adsorption and precipitation, respectively; $c_{\mathrm{M}}$ is the equilibrium molarity of dissolved $\mathrm{M}$; and $c_{\mathrm{M}, \mathrm{sat}}$ is the molarity of $\mathrm{M}$ saturated with the pure phase of $\mathrm{M}$ at the conditions of interest (for $\mathrm{M}^{\mathrm{II}}$ hydroxide, $c_{\mathrm{M} \text {,sat }} \approx K_{\mathrm{ppt}} /\left[\mathrm{OH}^{-}\right]^{2}$ ). Rodda et al. [17] have shown that Eq. (23) with three adjustable parameters $\Gamma_{\mathrm{C}}, c_{\mathrm{M}, \text { sat }}$ and $b^{\prime}$ provides a good fit to $\mathrm{Zn}$ adsorption isotherms on goethite. Instead of fitting, it must be possible to find the last two parameters from general thermodynamic data, - one of the tasks for extracting the BET SACT from the BET isotherm equation applied to sorption on mineral surfaces. This ongoing work is of interest because the transition from adsorption to surface precipitation has been observed, e.g., for nickel sorption on clay minerals [51].

The empirical Freundlich isotherm

$$
\Gamma_{\mathrm{M}}=k_{\mathrm{f}} c_{\mathrm{M}}^{m}
$$

describes adsorption of $\mathrm{M}$ onto heterogeneous surfaces with exponential distribution of site energies (rare sites have higher binding energies), such that for all sites of the same energy, the Langmuir isotherm is applicable [3]. In Eq. (24), parameters are $k_{\mathrm{f}}$ describing the adsorption density under some "standard" conditions $\left(\Gamma_{\mathrm{M}}=k_{\mathrm{f}}\right.$ when $\left.c_{\mathrm{M}}=1\right)$, and the power $m$ which indicates how dramatically the binding strength changes as the adsorption density $\Gamma_{\mathrm{M}}$ increases. Generalized Freundlich isotherms (also combined with the Langmuir isotherm) were considered for adsorption of metals on ferrihydrite [16]. The Freundlich isotherm appears attractive for describing sorption of trace amounts of strongly sorbing radionuclides on mineral surfaces that are heterogeneous in the above sense. Implementation of the Freundlich SACT is desirable because this may reduce a multisite SCM to a single-site model capable of describing the metal adsorption onto an energetically heterogeneous MWI. The difficulty here is that Eq. (24) is not referenced to infinite dilution. 
Thermodynamic models are of essentially macroscopic nature. Modeling examples for $\mathrm{U}^{\mathrm{VI}}$ sorption on goethite presented above show that the SCM fitting should not be expected to provide mechanistic conclusions about surface interactions on molecular level in the absence of independent atomic scale (e.g. crystallographic) information. It is known that $\mathrm{U}^{\mathrm{VI}}$ - the most ubiquitous actinide - binds onto oxide surfaces (quartz, goethite, HFO, gibbsite) with its two equatorial oxygens in a doubly-coordinated fashion [44, 52]. However, this does not necessarily mean that an SCM with a bidentate uranyl surface complex will yield optimal fits because the major uncertainty lies in defining the surface binding site. If the site density $\Gamma_{\mathrm{C}, 2}$ is taken as an adjustable parameter then equally good fits at the same $K_{\mathrm{S}, \mathrm{UL}}$ value can be obtained using QCA SACT corrections (Eq. (17)) for 1-, 2-, 3-, or 4-dentate cases solely by manipulating the $\Gamma_{\mathrm{C}, 2}$ value. However, a priori constraining $\Gamma_{\mathrm{C}, 2}$ value makes the SCM much more sensitive to such non-ideality corrections. Good fits then require an adjustment of $K_{\mathrm{S}, \mathrm{UL}}$ value and can be obtained only for certain "dentateness" $n$ (in QCA SACT) or certain $\alpha_{\mathrm{F}}$ parameter value (in Frumkin SACT).

With a priori known site densities utilized in SACT corrections, the SCMs, especially non-electrostatic, become more constrained and better linked with the available knowledge about the microscopic binding mechanisms, the surface geometry, reactive sites and their density, and the distribution of crystal plane areas on mineral particles. Such information, obtained from the combined crystallographic, spectroscopic and ( $a b$ initio) molecular dynamics data, enters the SCM in the form of stoichiometries of surface complexes on different binding site types with site charges, location, and maximum densities on surface planes. In our example, two alternative values of site density $\Gamma_{\mathrm{C}, 2}$ for innersphere uranyl surface binding on goethite could be estimated assuming that two adjacent surface oxygens represent one site. Modeling with the Frumkin SACT (Eq. (20)) suggests that at $\Gamma_{\mathrm{C}, 2}=3.0 \mu \mathrm{mol} \mathrm{m}^{-2}\left(N_{\mathrm{C}, 2}=1.81 \mathrm{~nm}^{-2}\right)$, good fits require positive $\alpha_{\mathrm{F}}$ values (attraction), consistent with the tendency of uranyl to form olygomeric complexes at elevated dissolved concentrations. However, using $\Gamma_{\mathrm{C}, 2}=$ $4.5 \mu \mathrm{mol} \mathrm{m}^{-2}\left(N_{\mathrm{C}, 2}=2.7 \mathrm{~nm}^{-2}\right)$, the best fits were obtained with significant negative $\alpha_{\mathrm{F}}$ values, perhaps reflecting some repulsive interactions between the axial oxygens of adjacent surface-bound uranyl moieties. To draw more precise conclusions, structural binding sites specific for uranyl on goethite surfaces need to be identified.

Macroscopic effects related to "dentateness" $n$, site density $\Gamma_{\mathrm{C}}$, lateral interactions $\left(\alpha_{\mathrm{F}}\right)$, or multi-layer adsorption, are only manifested in SCM curves corresponding to moderateor high surface loadings, i.e. at relatively low sorbent and high dissolved adsorbate concentrations. This is the case for the ubiquitous actinide $\mathrm{U}^{\mathrm{VI}}$ that can reach sub-millimolar concentrations in oxidized aqueous solutions exposed to air. However, at low surface coverage and trace concentrations, typical for most other actinides and fission products, their sorption generally tends to obey the linear isotherm (where SACTs play almost no role) or, on heterogeneous surface sites, the Freundlich isotherm.

It can be concluded that introduction of SACT with the elimination of multiple site balances opens a feasible way to construct simpler, better constrained, and more reliable
SCMs (both in GEM and LMA implementations), usable from trace to high concentrations, and embracing phenomena from trace chemisorption to surface precipitation. The SACT corrections suggested in this paper do not replace existing SCMs, but enhance them by embedding some physically realistic dependencies of adsorbed densities on properties of surfaces and binding sites, which should bring thus extended SCMs closer to reality and gain a better understanding of retention processes under the conditions of interest. Such enhanced models can be set up in element stoichiometry basis; they will have less model parameters and surface species than SCMs existing by now, and will operate with standard-state equilibrium constants or standard molar Gibbs energies that should eventually build up a unified sorption thermodynamic data base.

\section{List of Abbreviations}

$\begin{array}{ll}\text { BET } & \text { Brunauer-Emmett-Teller (isotherm) } \\ \text { BS } & \text { Basic Stern EDL model } \\ \text { CC } & \text { Constant-Capacitance EDL model } \\ \text { DL } & \text { Diffuse Double Layer EDL model } \\ \text { EDL } & \text { Electrical double layer } \\ \text { GEM } & \text { Gibbs energy minimization } \\ \text { GEMS } & \text { Gibbs energy minimization Selektor (code) } \\ \text { LMA } & \text { Law of mass action (code) } \\ \text { MUSIC } & \text { Multi-site complexation (adsorption model) } \\ \text { MWI } & \text { Mineral-water interface } \\ \text { PSI } & \text { Paul Scherrer Insitute } \\ \text { QCA } & \text { Quasi-chemical approximation } \\ \text { SACT } & \text { Surface activity coefficient term } \\ \text { SAT } & \text { Surface activity term [27] (obsolete) } \\ \text { SCM } & \text { Surface complexation model } \\ \text { TL } & \text { Triple Layer EDL model }\end{array}$

\section{List of Symbols}

$a_{\mathrm{B}} \quad$ activity (relative) of solute species B $a_{\mathrm{S}, \mathrm{B}} \quad$ activity (relative) of adsorbed species B

$\alpha_{\mathrm{F}} \quad$ Frumkin lateral interaction parameter

$A \quad$ A sorbent (reactive) surface area $\left(\mathrm{m}^{2}\right)$

$A_{\mathrm{S}} \quad$ specific surface area of the sorbent $\left(\mathrm{m}^{2} \mathrm{~g}^{-1}\right)$

$b^{\prime} \quad$ parameter of BET isotherm (Eq. (23))

$c^{\mathrm{o}} \quad$ standard molar concentration (1 M)

$c_{\mathrm{B}} \quad$ molar concentration of solute species $\mathrm{B}$

$\mathrm{C}_{1}, \mathrm{C}_{2}$ TL model capacitance densities $\left(\mathrm{F} \mathrm{m}^{-2}\right)$

$F \quad$ Faraday's constant $\left(96485.31 \mathrm{C} \mathrm{mol}^{-1}\right)$

$\varphi \quad$ relative electrostatic potential (on EDL plane)

$G_{298}^{\text {o }} \quad$ Standard molar Gibbs energy at $T=298 \mathrm{~K}$

$\gamma_{\mathrm{B}} \quad$ activity coefficient of solute species B

$\gamma_{\mathrm{E}, \mathrm{B}} \quad$ electrostatic surface activity coefficient term

$\gamma_{\mathrm{S}, \mathrm{B}} \quad$ Non-electrostatic surface activity coefficient

$\gamma_{\mathrm{F}, \mathrm{B}} \quad$ surface activity coefficient term (Frumkin)

$\gamma_{\mathrm{L}} \quad$ competitive Langmuir SACT

$\gamma_{\mathrm{L}, \mathrm{B}} \quad$ surface activity coefficient term (Langmuir)

$\gamma_{\mathrm{L}, \mathrm{B}}^{(n)} \quad$ SACT for $n$-dentate species B $\mathrm{B}^{(\mathrm{n})}(\mathrm{QCA})$

$\Gamma_{\mathrm{o}} \quad$ adsorbed density at standard state $\left(\mathrm{mol} \mathrm{m}^{-2}\right)$

$\Gamma_{\mathrm{B}} \quad$ adsorbed density of species B $\left(\mathrm{mol} \mathrm{m}^{-2}\right)$

$\Gamma_{\mathrm{C}} \quad$ site density parameter $\left(\mathrm{mol} \mathrm{m}^{-2}\right)$ 
$\Gamma_{\sum} \quad$ total density of competing adsorbed species

$K_{\mathrm{j}}^{\text {int }} \quad$ intrinsic adsorption constant (in LMA SCMs)

$K_{\mathrm{F}, \mathrm{B}} \quad$ Frumkin apparent binding constant

$K_{\mathrm{L}, \mathrm{B}} \quad$ Langmuir apparent binding constant

$K_{\mathrm{S}, \mathrm{B}} \quad$ standard-state adsorption equilibrium constant

$k_{\mathrm{f}} \quad$ constant in Freundlich isotherm (Eq. (24))

$m$ molality; power in Freundlich isotherm

$m^{\mathrm{o}} \quad$ standard molal concentration $\left(1 \mathrm{~mol} \mathrm{~kg}^{-1}\right)$

$m_{\mathrm{B}} \quad$ molal concentration of solute species B

$M_{\mathrm{S}} \quad$ molar mass of the sorbent $\left(\mathrm{g} \mathrm{mol}^{-1}\right)$

$\mu_{\mathrm{B}} \quad$ chemical potential of solute species B

$\mu_{\mathrm{B}}^{\mathrm{o}} \quad$ standard-state chemical potential of $\mathrm{B}$

$N_{\mathrm{A}} \quad$ Avogadro's number $\left(6.022137 \times 10^{23}\right)$

$N_{\mathrm{B}} \quad$ number density of adsorbed B $\left(\mathrm{nm}^{-2}\right)$

$N_{\mathrm{C}} \quad$ site number density parameter $\left(\mathrm{nm}^{-2}\right)$

${ }^{(n)}, n \quad$ dentateness (number of sites occupied by B)

$n_{\mathrm{B}} \quad$ amount of chemical species B (moles)

$n_{\mathrm{S}} \quad$ amount of the sorbent (moles)

$n_{\mathrm{S}, \mathrm{B}} \quad$ amount of adsorbed species B (moles)

$n_{\sum} \quad$ total amount of components (on surface)

$n_{\mathrm{M} \text { tot }} \quad$ total amount of surface binding sites

$q_{\mathrm{B}} \quad$ sorbed density of B (per unit mass or volume)

$q_{\mathrm{C}} \quad$ sorption capacity (per unit mass or volume)

$r_{\mathrm{B}} \quad$ relative content of solute species $\mathrm{B}$

$r_{\mathrm{S}, \mathrm{B}} \quad$ relative content of adsorbed species B

$r_{\mathrm{W}} \quad$ relative content of water-solvent $\mathrm{W}$

$R \quad$ universal gas constant $\left(8.31451 \mathrm{~J} \mathrm{~K}^{-1} \mathrm{~mol}^{-1}\right)$

$\sigma \quad$ surface charge density $\left(\mathrm{C} \mathrm{m}^{-2}\right)$

$T$ temperature (in $\mathrm{K}$ or ${ }^{\circ} \mathrm{C}$ where appropriate)

$\theta^{\circ} \quad$ standard-state surface coverage fraction

$\theta_{\mathrm{B}} \quad$ surface coverage fraction of adsorbed B

$x^{\mathrm{o}} \quad$ standard-state mole fraction

$x_{\mathrm{B}} \quad$ mole fraction of phase component B

$x_{\mathrm{W}} \quad$ mole fraction of water-solvent $\mathrm{W}$

$z_{\mathrm{B}} \quad$ charge number of (adsorbed) species B

Acknowledgment. The text clarity has been improved thanks to thoughtful comments by Jörg Hadermann and two anonymous reviewers. Partial financial support from Nagra (Swiss National Cooperative for the Disposal of Radioactive Waste), Wettingen, is gratefully appreciated.

\section{References}

1. Davis, J. A., Kent, D. B.: Surface complexation modeling in aqueous geochemistry. In: Mineral-water Interface Chemistry. (Hochella, M. F., White, A. F., eds.) Vol. 23, Rev. Mineral, Washington, DC (1990).

2. Langmuir, D.: Aqueous Environmental Geochemistry. Prentice Hall, New York (1997), p. 600.

3. Benjamin, M. M.: Water Chemistry. McGraw Hill, Boston e.a. (2002), p. 668.

4. Lützenkirchen, J.: Surface complexation models of adsorption. In: Encyclopedia of Surface and Colloid Science. (Hubbard, A., ed.) Marcel Dekker Inc., New York (2002).

5. Bradbury, M. H., Baeyens, B.: A mechanistic description of $\mathrm{Ni}$ and $\mathrm{Zn}$ sorption on Na-montmorillonite. Part II: Modelling. J. Contam. Hydrol. 27, 223 (1997).

6. Bradbury, M. H., Baeyens, B.: Modelling the sorption of $\mathrm{Zn}$ and $\mathrm{Ni}$ on Ca-montmorillonite. Geochim. Cosmochim. Acta 63, 325 (1999).

7. Bradbury, M. H., Baeyens, B.: Sorption of $\mathrm{Eu}$ on $\mathrm{Na}$ and $\mathrm{Ca}-$ montmorillonites: experimental investigations and modelling with cation exchange and surface complexation. Geochim. Cosmochim. Acta 66, 2325 (2002).
8. Bradbury, M. H., Baeyens, B.: Experimental measurements and modeling of sorption competition on montmorillonite. Geochim. Cosmochim. Acta 69, 4187 (2005).

9. Bradbury, M. H., Baeyens, B.: Modelling the sorption of Mn(II), $\mathrm{Co}(\mathrm{II}), \mathrm{Ni}(\mathrm{II}), \mathrm{Zn}(\mathrm{II}), \mathrm{Cd}(\mathrm{II}), \mathrm{Eu}(\mathrm{III}), \mathrm{Am}(\mathrm{III}), \mathrm{Sn}(\mathrm{IV}), \mathrm{Th}(\mathrm{IV})$, $\mathrm{Np}(\mathrm{V})$ and $\mathrm{U}(\mathrm{VI})$ on montmorillonite: linear free energy relationships and estimates of surface binding constants for some selected heavy metals and actinides. Geochim. Cosmochim. Acta 69, 875 (2005).

10. Baeyens, B., Bradbury, M. H.: A mechanistic description of Ni and $\mathrm{Zn}$ sorption on Na-montmorillonite. Part I: titration and sorption measurements. J. Contam. Hydrol. 27, 199 (1997).

11. Poinssot, C., Baeyens, B., Bradbury, M.: Experimental and modelling studies of caesium sorption on illite. Geochim. Cosmochim. Acta 63, 3217 (1999).

12. Somorjai, G. A.: Thermodynamics of Surfaces. Introduction to Surface Chemistry and Catalysis. Wiley, New York (1994), p. 271.

13. Tóth, J.: Uniform interpretation of gas/solid adsorption. Adv. Colloid Interface Sci. 55, 1 (1995).

14. Angove, M. J., Wells, J. D., Johnson, B. B.: The influence of temperature on the adsorption of cadmium(II) and cobalt(II) on goethite. J. Colloid Interface Sci. 211, 281 (1999).

15. Fokkink, L. G. J., de Keizer, A., Lyklema, J.: Temperature dependence of cadmium adsorption on oxides. J. Colloid Interface Sci. 135, 118 (1990)

16. Kinniburgh, D. G., Barker, J. A., Whitfield, M.: A comparison of some simple adsorption isotherms for describing divalent cation adsorption by ferrihydrite. J. Colloid Interface Sci. 95, 370 (1983)

17. Rodda, D. P., Johnson, B. B., Wells, J. D.: Modeling the effect of temperature on adsorption of lead(II) and zinc(II) onto goethite at constant pH. J. Colloid Interface Sci. 184, 365 (1996).

18. Benjamin, M. M., Leckie, J. O.: Multiple-site adsorption of Cd, $\mathrm{Cu}, \mathrm{Zn}$, and $\mathrm{Pb}$ on amorphous iron oxyhydroxide. J. Colloid Interface Sci. 79, 209 (1981).

19. Benjamin, M. M., Leckie, J. O.: Competitive adsorption of Cd, $\mathrm{Cu}, \mathrm{Zn}$, and $\mathrm{Pb}$ on amorphous iron oxyhydroxide. J. Colloid Interface Sci. 83, 410 (1981).

20. LaViolette, R. A., Redden, G. D.: Comment on "Modeling the mass-action expression for bidentate adsorption". Environ. Sci. Technol. 36, 2279 (2002).

21. Sverjensky, D. A.: Standard states for the activities of mineral surface sites and species. Geochim. Cosmochim. Acta 67, 17 (2003)

22. Kallay, N., Preočanin, T., Žalac, S.: Standard states and activity coefficients of interfacial species. Langmuir 20, 2986 (2004).

23. Wingrave, J. A.: Single cation adsorption equation for the solution - metal oxide interface. J. Colloid Interface Sci. 183, 579 (1996).

24. Sposito, G.: On the surface complexation model of the oxideaqueous solution interface. J. Colloid Interface Sci. 91, 329 (1983).

25. Hiemstra, T., van Riemsdijk, W. H.: On the relationship between surface structure and ion complexation of oxide-solution interfaces. In: Encyclopedia of Surface and Colloid Science. (Hubbard, A., ed.), Marcel Dekker Inc., New York (2002).

26. Kulik, D. A.: Sorption modelling by Gibbs energy minimisation: Towards a uniform thermodynamic database for surface complexes of radionuclides. Radiochim. Acta 90, 815 (2002).

27. Kulik, D. A.: A Gibbs energy minimization approach to modelling sorption equilibria at the mineral-water interface: Thermodynamic relations for multi-site-surface complexation. Am. J. Sci. 302, 227 (2002).

28. Benjamin, M. M.: Modeling the mass-action expression for bidentate adsorption. Environ. Sci. Technol. 36, 307 (2002).

29. Tamura, H., Mita, K., Tanaka, A., Makoto, I.: Mechanism of hydroxylation of metal oxide surfaces. J. Colloid Interface Sci. 243, 202 (2001).

30. De Boer, J. H.: The Dynamical Character of Adsorption. $2^{\text {nd }}$ edn., Clarendon Press, Oxford (1968) p. 239.

31. Lützenkirchen, J.: Surface Complexation Models of Adsorption: a Critical Survey in the Context of Experimental Data. In: Adsorption: Theory, Modeling, and Analysis. (Tóth, J., ed.) Marcel Dekker, New York (2002). 
32. Anderson, G. M., Crerar, D. A.: Thermodynamics in Geochemistry: the Equilibrium Model. Oxford Univ. Press, New York (1993) p. 588.

33. Goldberg, S.: Sensitivity of surface complexation modeling to the surface site density parameter. J. Colloid Interface Sci. 145, 1 (1991).

34. Stumm, W.: Chemistry of the Solid-Water Interface. Wiley, New York (1992), p. 428.

35. Tamura, H., Katayama, N., Furuichi, R.: Modeling of ion-exchange reactions on metal oxides with the Frumkin isotherm. 1. Acidbase and charge characteristics of $\mathrm{MnO}_{2}, \mathrm{TiO}_{2}, \mathrm{Fe}_{3} \mathrm{O}_{4}$, and $\mathrm{Al}_{2} \mathrm{O}_{3}$ surfaces and adsorption affinity of alkali metal ions. Environ. Sci. Technol. 30, 1198 (1996).

36. Tamura, H.: Theorization on ion-exchange equilibria: activity of species in 2-D phases. J. Colloid Interface Sci. 279, 1 (2004).

37. Pivovarov, S.: Acid-base properties and heavy and alkaline earth metal adsorption on the oxide-solution interface: non-electrostatic model. J. Colloid Interface Sci. 206, 122 (1998).

38. Morel, F. M. M., Hering, J. G.: Principles and Applications of Aquatic Chemistry. Wiley, New York (1993), p. 588

39. Hummel, W., Berner, U. R., Curti, E., Pearson, Jr., F. J., Thoenen, T.: Nagra-PSI Chemical Thermodynamic Database. Version 01/01, Universal Publishers/Upubl.com, New York (2002), p. 600.

40. Giammar, D. E., Hering, J. G.: Time scales for sorption-desorption and surface precipitation of uranyl on goethite. Environ. Sci. Technol. 35, 3332 (2001)

41. Gao, Y., Wahi, R., Kan, A. T., Folkner, J. C., Colvin, V. L., Tomson, M. B.: Adsorption of cadmium on anatase nanoparticles effect of crystal size and pH. Langmuir 20, 9585 (2004).

42. Villalobos, M., Trotz, M. A., Leckie, J. O.: Surface complexation modeling of carbonate effects on the absorption of $\mathrm{Cr}(\mathrm{VI})$, $\mathrm{Pb}(\mathrm{II})$, and $\mathrm{U}(\mathrm{VI})$ on goethite. Environ. Sci. Technol. 35, 3849 (2001).
43. Villalobos, M., Leckie, J. O.: Surface complexation modeling and FTIR study of carbonate adsorption of goethite. J. Colloid Interface Sci. 235, 15 (2001).

44. Sylwester, E. R., Hudson, E. A., Allen, P. G.: The structure of uranium(VI) sorption complexes on silica, alumina and motmorillonite. Geochim. Cosmochim. Acta 64, 2431 (2000).

45. Westall, J. C., Hohl, H.: A comparison of electrostatic models for the oxide/solution interface. Advan. Colloid Interface Sci. 12, 265 (1980).

46. Westall, J. C.: Modeling of the association of metal ions with heterogeneous environmental sorbents. Mater. Res. Soc. Symp. Proc. 353, 937 (1995).

47. Lützenkirchen, J., Boily, J.-F., Lövgren, L., Sjöberg, S.: Limitations of the potentiometric titration technique in determining the proton active site density on goethite surfaces. Geochim. Cosmochim. Acta 66, 3389 (2002).

48. Tadanier, C. J., Eick, M. J.: Formulating the charge-distribution multisite surface complexation model using FITEQL. Soil Sci. Soc. Am. J. 66, 1505 (2002).

49. Steele, H. M., Wright, K., Hillier, I. H.: Modelling the adsorption of uranyl on the surface of goethite. Geochim. Cosmochim. Acta 66, 1305 (2002).

50. Kulik, D.: Standard molar gibbs energies and activity coefficients of surface complexes (thermodynamic insights). In: Surface Complexation Modelling. (Lützenkirchen, J., ed.), Elsevier, Amsterdam (2006), p. 96, in press.

51. Scheidegger, A. M., Sparks, D. L.: A critical assessment of sorption-desorption mechanisms at the soil mineral/water interface. Soil Sci. 161, 813 (1996)

52. Waite, T. D., Davis, J. A., Payne, T. E., Waychunas, G. A., Xu, N.: Uranium(IV) adsorption to ferrihydrite: Application of a surface complexation model. Geochim. Cosmochim. Acta 58, 5465 (1994). 